\title{
Unresolved issues, dilemmas and points of interest in thyroid cancer: A current perspective
}

\author{
Nicholas J Sarlis ${ }^{1}$, Loukas Gourgiotis ${ }^{2}$
}

${ }^{1}$ The University of Texas - M. D. Anderson Cancer Center, Houston, Texas 77030, USA, and ${ }^{2}$ National Institute of Diabetes, Digestive, and Kidney Diseases, National Institutes of Health, Bethesda, MD 20892, USA

\begin{abstract}
Thyroid cancer (TC) is the commonest endocrine malignancy. In the overwhelming majority of cases, thyroid carcinomas are well-differentiated malignancies that respond favorably to treatment; however, this outcome cannot be absolutely guaranteed. The absence of large prospective randomized clinical trials in TC-due to its low incidence and protracted clinical course in cases with persistent/recurrent metastatic disease - results in considerable debates regarding the optimal treatment and follow-up regimens in this malignancy. Some of these debates originated several decades ago, yet are still ongoing despite interim advancements in other domains of oncology. Here we discuss what we believe are the issues of major controversy in TC; these are mentioned in the following non-exhaustive list: (i) the optimal management of solitary and multiple thyroid nodules; (ii) the role of basal calcitonin measurements in the diagnostic investigation of nodular thyroid disease; (iii) the extent of the initial operation after establishment of the diagnosis of TC; (iv) the intensity and frequency of radioactive iodine (RAI; $\left.{ }^{131} \mathrm{I}\right)$ therapies (especially in patients with persistent/recurrent metastatic disease); (v) the degree and duration of long-term thyroid hormone suppression therapy (THST) required for optimal outcomes in TC patients; (vi) the optimal management of patients with RAI-refractory disease or other "high-risk" clinicopathologic features; and, finally, (vii) the optimal algorithm for lifelong follow-up of TC patients after their initial treatment. We present elements of the above controversies as pertinent to the various types of TC. We have opted for breadth rather than depth of commentary, at the same time providing the reader with extended up-to-date bibliography.
\end{abstract}

Key Words: Thyroid cancer, Radioiodine, Thyroid hormone suppression therapy, Follow-up, Thyroid nodules, Calcitonin, Thyroglobulin, Thyroidectomy.

Address correspondence and requests for reprints to: Nicholas J. Sarlis, MD, PhD, FACE, FACP, Associate Professor of Medicine Dept. of Endocrine Neoplasia \& Hormonal Disorders, The University of TX - M. D. Anderson Cancer Center, 1515 Holcombe Blvd. - Unit 435, Houston, TX 77030, USA, Tel.: +1-713-792-2841,

Facsimile: +1-713-794-4065, e-mail: njsarlis@mdanderson.org

Received 11-03-04, Revised 24-06-04, Accepted 30-06-04

\section{INTRODUCTION}

In this contribution, we focus on current controversies and dilemmas in thyroid carcinoma (TC). We categorize these, as yet unresolved, questions, dilemmas, and issues as relevant to TC biological behavior, diagnostic approach at the time of initial presentation, and clinical management (including antitumor 


\begin{tabular}{|c|c|}
\hline ABBREVIATIC & NS \\
\hline $\mathrm{ACTH}$ & adrenocorticotropin \\
\hline ATC & anaplastic thyroid cancer \\
\hline BTA & British Thyroid Association (U.K.) \\
\hline $\mathrm{CCH}$ & C-cell hyperplasia \\
\hline CEA & carcinoembryonic antigen \\
\hline CG-A & chromogranin-A \\
\hline $\mathrm{CNS}$ & central nervous system \\
\hline $\mathrm{CRH}$ & corticotropin-releasing hormone \\
\hline CT & computed tomography \\
\hline DSV & diffuse sclerosing variant \\
\hline EBRT & external beam radiotherapy \\
\hline FA & follicular adenoma \\
\hline FAP & familial adenomatous polyposis coli \\
\hline FDG-PET & $\begin{array}{l}{ }^{18} \mathrm{~F} \text {-fluorodeoxyglucose positron emission tomo- } \\
\text { graphy }\end{array}$ \\
\hline FMTC & familial MTC \\
\hline FNAB & fine needle aspiration biopsy \\
\hline FPTC & familial PTC \\
\hline FTC & follicular thyroid cancer \\
\hline FV & follicular variant \\
\hline $\mathrm{HCC}$ & Hurthle-cell carcinoma \\
\hline 5-HT & 5-hydroxytryptamine (serotonin) \\
\hline IRMA/ICMA & $\begin{array}{l}\text { immuno(radio/chemilumi)metric assay (for thyro- } \\
\text { globulin) }\end{array}$ \\
\hline $\mathrm{LCH}$ & Langerhans'-cell histiocytosis \\
\hline MDACC & M. D. Anderson Cancer Center (Houston, TX) \\
\hline MEN & multiple endocrine neoplasia \\
\hline MIBG & meta-iodobenzylguanidine \\
\hline MRI & magnetic resonance imaging \\
\hline MRND & modified radical neck dissection \\
\hline MSKCC & $\begin{array}{l}\text { Memorial-Sloan Kettering Cancer Center (New } \\
\text { York, NY) }\end{array}$ \\
\hline MSO & malignant struma ovarii \\
\hline MTC & medullary thyroid cancer \\
\hline $\mathrm{NCCN}$ & National Comprehensive Cancer Network (U.S.) \\
\hline NCI & National Cancer Institute (Bethesda, MD) \\
\hline PET & positron emission tomography \\
\hline PTC & papillary thyroid cancer \\
\hline RAI & radioactive iodine; ${ }^{131} \mathrm{I}$ \\
\hline rhTSH & recombinant human TSH \\
\hline RIA & radioimmunoassay \\
\hline SEER & Surveillance, Epidemiology, and End Results \\
\hline SV & solid variant \\
\hline $\mathrm{TC}$ & thyroid cancer; thyroid carcinoma \\
\hline TCV & tall cell variant \\
\hline $\operatorname{Tg}$ & thyroglobulin \\
\hline $\mathrm{TH}$ & thyroid hormone \\
\hline THST & thyroid hormone suppression therapy \\
\hline T/NTT & total or near-total thyroidectomy \\
\hline TSH & thyrotropin \\
\hline $\mathrm{U} / \mathrm{S}$ & ultrasonography \\
\hline VIP & vasoactive intestinal peptide \\
\hline WBS & whole body scan \\
\hline WDHA & $\begin{array}{l}\text { watery diarrhea-hypokalemia-achlorhydria syn- } \\
\text { drome }\end{array}$ \\
\hline
\end{tabular}

therapy and long-term follow-up). These points are presented for each pathologic type of TC, including rare malignancies. Throughout this review, we intersperse interesting, yet under-appreciated, management details ("pearls") pertinent to each section. If the clinician who deals with TC patients (among others, the Endocrinologist, Nuclear Medicine specialist, Pathologist, Oncologist, Surgeon, and Radiation Therapist) pays due attention to these details, s/he could potentially improve therapy outcome and follow-up strategy design in selected TC cases, especially those of patients with "clinically aggressive" disease.

\section{CONTROVERSIES IN TC DIAGNOSIS AT INITIAL PRESENTATION}

The epidemiology, diagnosis, differential diagnosis, and treatment of TC are inextricably entwined with those of nodular goiter and other benign thyroid disorders. Thyroid nodules are common. Their prevalence in two population-based studies - Framingham, MA, USA, and Whickham, England, UK - was 4.2 and $3.2 \%$, respectively ${ }^{1,2}$. However, the true prevalence of thyroid nodules demonstrated at autopsy is much greater, i.e. up to $50 \%$ in subjects with "clinically normal" thyroid glands ${ }^{3}$. With the increased use of newer imaging modalities, such as high-resolution neck ultrasonography (U/S), the discovery of thyroid incidentalomas has become commonplace. In two studies where patients were evaluated with neck U/S for primary hyperparathyroidism, thyroid nodules were found in up to $46 \%$ of them ${ }^{4,5}$. Furthermore, almost half of the patients presenting with a solitary clinically palpable thyroid nodule have additional nodule(s) detected by U/S; most of these are "unexpected" or occult lesions ${ }^{6}$. Several studies have shown that the risk of malignancy is the same in clinically obvious vs. occult (impalpable) thyroid nodules, i.e. around 5\%$6 \%$. These epidemiologic data can be a source of considerable anxiety for individual patients, despite the fact that clinically apparent $\mathrm{TC}$ remains a rather uncommon malignancy (in comparison with most other solid organ or head \& neck malignancies). In the United States, according to the Surveillance, Epidemiology, and End Results (SEER) program of the National Cancer Institute (NCI), TC prevalence in the general population is less than $0.1 \%$. This statistic notwithstanding, clinically inapparent - or occult $\mathrm{TC}$, defined as a lesion smaller than $10 \mathrm{~mm}$ that is 
unexpectedly found during autopsy or surgery, is quite common. The prevalence of "clinically silent" TC in North America averages $3.6 \%$, but rates as high as $36 \%$ have been reported in other countries ${ }^{10,11}$, possibly related to differences in iodine sufficiency of the ambient diet and the differential effect of a variety of other factors, including population age and ethnicity.

From the above data, it appears that clinically occult TC has minimal clinical importance. The very same data pose the dilemma of optimal management of incidentally discovered thyroid nodules, given the fact that the size threshold-among experienced examiners - for palpation of thyroid nodules is 1.0-1.5 $\mathrm{cm}$. Most experts advocate fine needle aspiration biopsy (FNAB) of all thyroid nodules larger than 1.0 $\mathrm{cm}^{12,13}$. By applying the above criterion and assuming that $\sim 40-50 \%$ of the population harbors inapparent thyroid nodules, as well as that $\sim 30 \%$ of these nodules will be greater than $1.0 \mathrm{~cm}$ in size, one would then conclude that $\sim 10-12 \%$ of the population could be candidates for a diagnostic FNAB. Theoretically, if all the above individuals were biopsied, and with an estimated $5 \%$ malignancy rate, up to $0.6 \%-0.7 \%$ of the general population could end up with a diagnosis of TC! This rationale could well create a public health conundrum, considering that the majority $(>80 \%)$ of the TCs diagnosed in this manner would never become clinically significant during an individual's lifetime. Therefore, it has been proposed that only nodules with certain ultrasonographic criteria should undergo FNAB. These criteria include: nodule size $>1.5$ $\mathrm{cm}$, irregular margins, presence of microcalcifications, and an intranodular vascular pattern, the latter being assessed by Doppler color flow U/S techniques ${ }^{14}$. Additional studies that focus on the optimal management of nodules that do not meet the above criteria for FNAB, or are too small to biopsy, are needed for refinement of currently available guidelines [available at Internet site: http://www.aace.com/clin/guidelines/ thyroid_nodules.pdf; site last accessed on July 7, $2004^{15}$ ]. This is especially true, as a few occult TCs may present with local or, rarely, even distant dissemination ${ }^{16}$.

In the context of the diagnostic evaluation of thyroid nodules, the role of thyroid scintigraphy $\left({ }^{123} \mathrm{I}\right.$ or ${ }^{99 \mathrm{~m}} \mathrm{Tc}$ ) is currently thought to be limited. Nevertheless, we believe that a thyroid scan should be performed only in cases of patients with: decreased se- rum thyrotropin (TSH), suspicion of ectopic thyroid tissue, or retrosternal extension of a goiter or mass ${ }^{17}$. Scintigraphically "hot" thyroid nodules are more likely to show cytologic features of "follicular neoplasm" on FNABs, as most of them are indeed benign (hyperfunctioning or "autonomous") follicular adenomas ${ }^{18}$. Of note, hyperfunctioning follicular TCs (FTCs) are rare $^{19}$.

The role of "screening" baseline plasma calcitonin measurements in the context of initial diagnosis of MTC remains controversial. Several studies have shown that FNAB can miss a diagnosis of MTC in up to $20 \%$ of cases, suggesting that an elevated basal calcitonin level in a patient with nodular thyroid disease is much more informative for MTC than an $\mathrm{FNAB}^{20}$. A basal calcitonin level (measured with a reliable double-site immunometric assay [IRMA or ICMA]) of less than $10 \mathrm{pg} / \mathrm{ml}$ can be considered "normal", with values above $100 \mathrm{pg} / \mathrm{ml}$ being clearly abnormal and requiring definite diagnosis with thyroidectomy ${ }^{20}$. Unfortunately, these cutoff values leave a "gray area" for calcitonin levels between 10 and $100 \mathrm{pg} / \mathrm{ml}$, a range that is predictive of MTC in only $13 \%-15 \%$ of cases ${ }^{21}$. Stimulation with pentagastrin + calcium can be useful in cases like these, since stimulated calcitonin levels above $100 \mathrm{pg} / \mathrm{ml}$ are highly indicative of MTC or the precancerous condition of C-cell hyperplasia $(\mathrm{CCH})^{22-25}$. Of note, these issues are further complicated by the current lack of availability of pentagastrin in North America.

Despite the aforementioned caveats, FNAB is the method of choice for the initial evaluation of thyroid nodules. The results of the FNAB are usually categorized into four diagnostic groups: benign (negative), malignant (positive), suspicious (indeterminate), and unsatisfactory (non-diagnostic) ${ }^{26}$. Unsatisfactory specimens are usually hypocellular/paucicellular, account for $5-15 \%$ of FNABs, and, in their presence, FNA sampling should be repeated ${ }^{27}$. Re-biopsy yields satisfactory results in about half of the cases, and U/S-guided FNAB can further increase this rate to $\sim 70 \%$. Despite this fact, an incidence of $\sim 10 \%-15 \%$ of unsatisfactory specimens remains. The risk of malignancy in nodules that have been subjected to multiple FNABs that yielded unsatisfactory specimens can be as high as $10 \%{ }^{28}$. Tissue core biopsy (TCB) or thyroid surgery may be necessary for diagnosis in these cases. An ipsilateral hemithyroidectomy and isthmusectomy can 
be used as the initial approach, particularly if the nodule is growing over time. The surgical pathology results from study of permanent sections usually provide the definitive answer with regard to the presence or absence of malignancy. The value of intraoperative frozen sections in such cases remains debatable (M. Merino, NIH, Bethesda, MD; personal communication).

The management of "suspicious" lesions, i.e. nodules that yielded adequate FNAB specimens that were still cytologically "indeterminate", remains controversial. These lesions include: hypercellular follicular lesions (especially when associated with a dearth of colloid and/or absence of lymphocytic thyroiditis features in the cytopathology specimen), follicular neoplasms, Hurthle-cell neoplasms, benign specimens with marked cellular atypia ${ }^{29,30}$. Approximately $20-25 \%$ of these "suspicious" lesions are eventually proven to be malignant (usually FTCs, but also follicular variant of PTCs, and, rarely, even MTCs) (30; A. Fili, NIH, Bethesda, MD; personal communication). Therefore, the currently recommended approach for cytologically suspicious lesions is surgical resection with an ipsilateral hemithyroidectomy and isthmusectomy ${ }^{31}$. The surgical specimen may also be examined by frozen section. As mentioned above, the diagnostic value of frozen sections in this setting remains a debatable issue. Some authorities believe that frozen sections are of limited value in regards to providing a definitive diagnosis of TC and, hence, unable to provide assistance with the decision to proceed (or not) with completion thyroidectomy during the time of the actual operation $^{32,33}$; others disagree with that assessment (A. El-Naggar, M. D. Anderson Cancer Center [MDACC], Houston, TX; personal communication).

\section{CONTROVERSIES IN PAPILLARY TC (PTC): PATHOLOGY AND PROGNOSIS}

PTCs represent the majority $(80 \%)$ of $\mathrm{TCs}^{34}$. In autopsy and surgical pathology studies, microscopic occult PTC ("papillary microcarcinoma") occurs in 5$35 \%$ of the population, either as an independent focus or in the form of microscopic malignant cell clusters within an otherwise benign nodule (e.g. nodular hyperplastic goiter or follicular adenoma). Notably, most such microcarcinomas never become apparent by clinical or imaging methods and, hence, remain well below clinical detectability ${ }^{35}$. The factors that "drive" only a minority of these "microcancers" to develop into clinically evident PTC remain unknown.

Patient characteristics indicating poorer PTC prognosis are: age at diagnosis $<15$ or $>45$, male sex, family history of TC, and previous exposure to neck radiation $^{36}$. Tumor variables associated with worse PTC prognosis are: size $>4.0 \mathrm{~cm}$; multifocality presence of extrathyroidal extension; presence of vascular invasion; aggressive tumor histological subtype (see below); advanced histologic grade with nuclear atypia; tumor aneuploidy; presence of areas of tumor necrosis; and presence of distant metastases ${ }^{36}$. Whether the presence of microscopic cervical and anterosuperior mediastinal lymph node metastases alters prognosis remains debatable. On the other hand, there is little doubt that bulky macroscopic cervical lymphadenopathy, as well as presence of mediastinal nodes deeper than the confines of the anterosuperior mediastinum (the latter, even when only microscopically infiltrated), can affect prognosis in a negative way. The overall 10 -yr survival of patients with PTC is $\sim 90-93 \%{ }^{34}$.

In addition to the "ordinary" or "common" variant of PTC, there are several subtypes (or variants) of PTC. These variants include ${ }^{37}$ : the relatively frequent "follicular variant" (PTC-FV, referred to as "mixed papillary-follicular" TC in older literature); the diffuse sclerosing variant (DSV); the tall-cell variant (TCV); the trabecular cell variant; the columnar-cell variant; the solid variant (SV; rare, specifically associated with radiation-induced PTC); and the cribriform variant (specifically occurring in the context of the autosomal dominant syndrome of familial adenomatous polyposis [FAP]). Apart from PTC-FV, all the above variants have been variably considered to demonstrate a more aggressive clinical behavior vs. that seen with "ordinary" $\mathrm{PTC}^{38-42}$.

Very rarely, PTC may arise as part of a genetic neoplasia syndrome, such as Cowden syndrome ${ }^{43}$, Peutz-Jeghers syndrome ${ }^{44}, \mathrm{FAP}^{45}$ or Carney complex ${ }^{46}$. Very few pedigrees have also been described with familial PTC (FPTC) in the absence of other syndromic features ${ }^{47,48}$. Extremely rarely, PTC can develop within a benign struma ovarii ${ }^{49}$.

\section{CONTROVERSIES IN FOLLICULAR TC (FTC): PATHOLOGY AND PROGNOSIS}

Follicular TC (FTC) represents $11 \%-13 \%$ of TCs ${ }^{34}$. 
Usually, these tumors are encapsulated. The same patient and tumor characteristics as for PTC are pertinent for prognosis of FTC (see previous section). The 10-yr survival for "minimally-invasive" FTCs is $85 \%$, in contradistinction to $\sim 45 \%$ for "grossly invasive" (or "more-than-minimally invasive") $\mathrm{FTCs}^{50}$. Overall, FTCs are believed to have an increased malignant potential vs. PTCs of the same stage, and tend to spread hematogenously to distant sites (mediastinum, lungs, bone, CNS, etc. $)^{51}$.

There are three additional subtypes (or variants) of FTC, other than the "ordinary" one. These variants include: the Hurthle- (or oxyphilic-) cell variant (or Hurthle-cell carcinoma [HCC]); the poorly-differentiated variant; and the insular variant. A considerable body of evidence suggests that these FTC variants may behave in a more aggressive fashion than "ordinary" FTC ${ }^{52-54}$. Very rarely, a tumor may present with mixed follicular and medullary components (FTCMTC "mixed" or "collision" tumors) ${ }^{55}$. Additionally, also rarely, FTC can develop within a benign struma ovarii $^{56}$.

As mentioned previously, at the time of initial diagnosis, FNAB is inadequate in differentiating among benign follicular adenomas (FAs), FTCs (and its subtypes), and PTCs-FV ${ }^{57}$. This distinction eventually has to be made by examination of surgical pathology or tissue core biopsy specimens. In contrast to other solid malignancies, immunohistochemical study of "standard" proliferative markers (e.g. p53, $\mathrm{K}_{\mathrm{i}} 67$, PCNA, etc.) and other epithelial differentiation markers does not usually differentiate between benign and malignant lesions ${ }^{58}$; however, staining for galectin-3 has recently been reported to be consistently positive in FTCs, yet is rare in $\mathrm{FAs}^{59}$.

It is worth noting at this point that efforts towards prognostication of final outcome in patients with PTC and FTC based on clinical features at the time of initial presentation have been going on for more than 5 decades. These efforts have resulted in a multitude of staging systems specifically for TC. The aim of staging systems is to provide reliable risk assessment with regard to morbidity, mortality, and incidence of recurrence, so that they provide guidance to the clinician regarding the aggressiveness of primary or secondary treatment applied and the vigor of follow-up measures. Overall, the currently existing staging systems have not entirely achieved that goal, as TC dem- onstrates one of the widest ranges of malignant behavior of any other tumor type emanating from a cell of a defined histogenetic origin. On the other hand, staging systems can be very useful in long-term epidemiologic studies, as well as clinical research, since they aid in risk group stratification for retrospective analysis of TC natural history and treatment outcomes, as well as the design of prospective trials of novel treatment approaches. The currently published staging systems for TC include: pTNM (pathological tumornode-metastasis system, adopted by the American Joint Committee on Cancer [AJCC] and the Union Internationale Contre le Cancer [UICC]), NTCTCS (National Thyroid Cancer Treatment Cooperative Study; "National Registry group"), EORTC (European Organization for Research and Treatment of Cancer), MACIS (Metastasis, age, completeness of resection, invasion, \& size), AGES (Age, grade, extent, size), and AMES (Age, distant metastasis, extent \& size of primary tumor), Clinical Class/University of Chicago, and Ohio State University (OSU) staging systems. The most extensively used and validated systems are pTNM and NTCTCS. We also believe that these two systems reflect the biology of TC better than the other available staging systems. The pTNM system was revised in $2002^{60,61}$, while NTCTCS has not been altered since its initial conception more than 15 years ago ${ }^{62,63}$. These two systems are shown in Tables 1 and 2.

\section{PTC AND FTC: CONTROVERSIES AND DEBATES IN THEIR MANAGEMENT AND FOLLOW-UP}

PTC and FTC management comprises 5 major phases: diagnosis, initial surgery, remnant ablation, thyroid hormone suppression of TSH (THST), and long-term follow-up. Considerable debate surrounds all these phases, mainly due to the absence of prospective randomized trials on TC management. Practice guidelines have recently been published by experts from comprehensive cancer centers in the U.S. ${ }^{15,64}$, as well as the British Thyroid Association (BTA) ${ }^{65}$. The relevant Internet sites are as follows: http:// www.nccn.org/physician_gls/f_guidelines.html, http:// www.aace.com/clin/guidelines/thyroid_carcinoma.pdf, and http://www.british-thyroid-association.org/ guidelines.htm (sites were last accessed on July 7, 2004). Nevertheless, consensus has not been reached 
Table 1. Thyroid Carcinoma Staging according to the TNM/UICC System, $6^{\text {th }}$ Edition $(2002)(60,61)$

\section{Primary Tumor Size}

Tx Primary tumor cannot be assessed

T0 No evidence of primary tumor

T1 Tumor size: maximal $2 \mathrm{~cm}$, limited to the thyroid

T2 Tumor size: $>2 \mathrm{~cm}$ and $\leq 4 \mathrm{~cm}$, limited to the thyroid

T3 Tumor size: $>4 \mathrm{~cm}$, limited to the thyroid, or any tumor with minimal extrathyroid extension (i.e., to sternothyroid muscle or perithyroid soft tissues)

T4 T4a: tumor extends beyond the thyroid capsule and invades subcutaneous soft tissues, larynx, trachea, esophagus, or recurrent laryngeal nerve

T4b: tumor invades prevertebral fascia, mediastinal vessels, or encases carotid artery

Presence of Regional Lymph Node Metastasis

$\mathrm{Nx} \quad$ Regional lymph nodes cannot be assessed

No No regional lymph node metastasis

N1 Regional lymph node metastasis

N1a Metastasis in Level VI (pretracheal and paratracheal, including prelaryngeal and Delphian lymph nodes)

N1b Metastasis in other unilateral, bilateral, or contralateral cervical or mediastinal lymph nodes

Presence of Distant Metastasis

Mx Distant metastasis cannot be assessed

M0 No distant metastasis

M1 Distant metastasis

Derivant TNM/UICC Clinicopathologic Stages

$\begin{array}{ll}\text { Stage I } & \text { Tx Nx M0 <45 yrs } \\ & \text { T1 N0 M0 } \geq 45 \text { yrs } \\ \text { Stage II } & \text { Tx Nx M1 <45 yrs } \\ & \text { T2 N0 M0 } \geq 45 \text { yrs } \\ \text { Stage III } & \text { T3 N0 M0 } \geq 45 \text { yrs } \\ & \text { T1-3 N1a M0 } \geq 45 \text { yrs } \\ \text { Stage IV } & \text { A: T1-3 N1b M0 } \geq 45 \text { yrs } \\ & \text { or T4a N0-1 M0 } \geq 45 \text { yrs } \\ & \text { B: T4b Nx M0 } \geq 45 \text { yrs } \\ & \text { C: Tx Nx M1 } \geq 45 \text { yrs }\end{array}$

Abbreviations: UICC: Union Internationale Contre le Cancer, yrs: years of age

among the experts participating in the these panels.

\section{i) Surgery}

In almost all cases of PTCs and FTCs greater than $1.0 \mathrm{~cm}$, a total or near-total thyroidectomy (T/NTT) is the initial surgical treatment of choice. Lobectomy alone - as the definitive initial surgery - is associated with a $5-10 \%$ recurrence in the contralateral lobe ${ }^{66}$, and a $\sim 25 \%-30 \%$ recurrence rate in the ipsilateral thyroid bed and neck lymph nodes ${ }^{36}$. There is also higher incidence of pulmonary metastases following lobectomy alone for PTC vs. performing a more complete surgery $^{66}$. There is evidence of increased relapse-free survival with T/NTT, although it is more difficult to demonstrate an effect on overall survival. Mazzaferri et al. showed that T/NTT reduces the risk of mortality by $50 \%$ after a median follow-up of 16 years. This effect was independent from subsequent administration of RAI treatment(s $)^{67}$. It has to be noted, however, that a remarkable total of 22,000 patient-years of follow-up was necessary to demonstrate the above effect of T/NTT. The guidelines published by the National Comprehensive Cancer Network (NCCN) in the U.S. recommend a total thyroidectomy with bilateral central compartment dissection; if lymph nodes are involved, lateral modified radical neck dissection is additionally advised ${ }^{64}$. The British Thyroid Association (BTA) recommends a total thyroidectomy plus removal of all lymph nodes in the central compartment of the neck, along with selective dissection of lateral cervical lymph nodes; there is no recommendation for routine radical neck dissection or more extensive explorations in multiple anatomical levels of cervical lymph nodes ${ }^{63}$. In selected cases of PTCs and FTCs with adverse prognostic factors, assuming that these are recognized and appreciated at the preoperative stage after appropriate risk stratification, a more aggressive surgical approach can be used. Moreover, a study suggested that in cases where a completion thyroidectomy is needed, if the latter is performed within 6 months from the initial partial thyroid resection, there is a significant survival advantage and a lower recurrence rate, as opposed to a completion operation performed more than 6 months after initial surgery $^{68}$.

\section{ii) Thyroid remnant $R A I$ ablation}

The universal treatment of all PTC/FTC patients with RAI for the ablation of thyroidal postoperative remnants, as well as RAI activity ("dose") to be administered, remain controversial issues. Most authors, including ourselves, believe that remnant ablation in all patients is justified for the following reasons: (a) it facilitates the subsequent follow-up of patients using 
Table 2. The National Thyroid Cancer Treatment Cooperative Study (NTCTCS) Registry Staging Classification for WDTC

\begin{tabular}{|c|c|c|c|c|}
\hline \multirow[t]{3}{*}{ Parameters considered } & \multicolumn{4}{|c|}{ Tumor Type } \\
\hline & \multicolumn{2}{|c|}{ Papillary TC } & \multicolumn{2}{|c|}{ Follicular TC } \\
\hline & Age $<45$ & Age $\geq 45$ & Age $<45$ & Age $\geq 45$ \\
\hline \multicolumn{5}{|l|}{ Primary tumor size $(\mathrm{cm})$} \\
\hline$<1$ & I & I & I & II \\
\hline $1-4$ & I & II & I & III \\
\hline$>4$ & II & III & II & III \\
\hline \multicolumn{5}{|l|}{ Primary tumor description } \\
\hline Microscopic multifocal & I & II & I & III \\
\hline Macroscopic multifocal or macroscopic tumor capsule invasion & I & II & II & III \\
\hline \multicolumn{5}{|l|}{ Extraglandular invasion } \\
\hline Microscopic & I & II & I & III \\
\hline Macroscopic & II & III & II & III \\
\hline Poor differentiation & NA & NA & III & III \\
\hline \multicolumn{5}{|l|}{ Metastases } \\
\hline Cervical lymph node metastases only & I & III & I & III \\
\hline Extracervical lymph node metastases (or worse) & III & IV & III & IV \\
\hline
\end{tabular}

(N.B.: Disease stage assigned to patients is the highest stage determined by any of the above clinicopathologic features).

Abbreviations: TC: thyroid carcinoma; WDTC: well-differentiated thyroid cancer.

serum thyroglobulin (Tg) as a tumor marker; (b) a large remnant might obscure the detection of cervical or lung metastases in long-term follow-up ${ }^{69}$; (c) the presence of a large remnant renders it difficult to achieve an appropriately elevated serum $\mathrm{TSH}$ - and thus RAI uptake by the tumor - in case RAI therapy is needed for tumor metastases; and (d) RAI ablation can also be cytocidal for concomitant micrometastases, as well as normal thyrocytes within the remnant that have a defined (above zero) lifelong potential for malignancy ${ }^{55}$.

In order to achieve optimal conditions for RAI ablation, serum TSH needs to be $>25 \mathrm{mU} / \mathrm{L}$. In the past, this was achieved by increasing endogenous (pituitary) TSH by instituting iatrogenic hypothyroidism after thyroidectomy. Recently, with the advent of recombinant human TSH (rhTSH), one can bypass the hypothyroid preparation and its associated morbidities. On-going studies are focusing on the question of relative efficacy of such an approach vs. "classic" hypothyroidism with regard to rates of achieving RAI ablation, but preliminary data suggest that rhTSH administration is equivalent to hypothyroid prepara$\operatorname{tion}^{70}$.

The optimal RAI dose for ablation is debatable and, to a certain degree, depends on the amount of thyroid tissue left behind after thyroidectomy. Lower doses $(\sim 30 \mathrm{mCi} ; 1.11 \mathrm{GBq})$ are appealing because they can be given on an outpatient basis. However, a recent meta-analysis showed that doses between 75 $100 \mathrm{mCi}(2.78-3.7 \mathrm{GBq})$ are more efficient than doses of $30 \mathrm{mCi}(1.11 \mathrm{GBq})$ in achieving complete remnant ablation ${ }^{36}$. Patients with more sinister prognostic factors would probably benefit from RAI ablation doses at the higher end of the spectrum (100-125 mCi; 3.7-4.63 MBq). Of note, a post-therapy RAI whole body scan should be performed after remnant ablation, as it can occasionally detect previously unappreciated or unsuspected sites of local or metastatic spread.

\section{iii) Thyroid hormone suppression therapy (THST)}

Although THST has been shown to significantly reduce recurrence and TC-specific mortality rates in both single institution studies ${ }^{71}$ and meta-analyses ${ }^{72}$, the minimum degree of TSH suppression to achieve this effect remains debatable. In PTC/FTC patients, the levothyroxine (LT4) dose needed to maintain serum TSH suppressed is $\sim 2.1-2.4 \mu \mathrm{g} / \mathrm{kg} /$ day, as opposed to the replacement therapy doses of $1.6-1.8 \mu \mathrm{g} / \mathrm{kg} / \mathrm{day}$ 
used in patients with hypothyroidism caused by nonmalignant disease ${ }^{73}$. To add more complexity to this issue, the LT4 dose required to achieve THST is dependent on the subject's age, with younger patients needing higher doses per unit weight than older patients $^{74}$.

In a French study by Pujol et al, persistently undetectable serum TSH levels $(<0.05 \mathrm{mU} / \mathrm{L})$ were associated with a longer relapse-free survival, as opposed to a serum TSH always being $>1.0 \mathrm{mU} / \mathrm{L}$; in the same study, the degree of TSH suppression was an independent predictor of disease recurrence ${ }^{75}$. Other studies, however, were unable to reproduce these results. In our opinion, for the vast majority of PTC/FTC patients, keeping a serum TSH just below the lower limit of normal (i.e. in the range of 0.1-0.4 $1.0 \mathrm{mU} / \mathrm{L}$ ) is appropriate. If there is evidence of persistent, recurrent or "clinically aggressive" disease, lower levels of "target" TSH may be considered, although one would always have to balance the risk-benefit ratio, given the fact that long-term subclinical hyperthyroidism is associated with increased risk of all-cause mortality. Finally, in low-risk patients who have reached a status of no evidence of disease and remain without recurrence for more than 10 years, a cogent argument can be made for those patients to continue LT4 therapy in hormonal replacement rather than TSH-suppressive doses (S. Sherman, MDACC, Houston, TX; personal communication).

\section{iv) Long-term follow-up}

The main methods of monitoring patients with PTC and FTC for the exclusion of persistent/recurrent disease are: measurement of serum thyroglobulin ( $\mathrm{Tg}$ ) levels, RAI whole body scans (WBSs), and neck U/S. A suggested scheme of follow-up of PTC/ FTC patients after primary therapy is shown in Figure 1 . In this scheme, specific emphasis is placed on the detection of persistent/recurrent disease, which should lead to appropriate therapeutic action (see section [v.]).

iv - a) Tg levels

The appropriate use of $\mathrm{Tg}$ as a TC "marker" presumes that patients have already undergone a T/NTT followed by thyroid remnant RAI ablation; otherwise, $\mathrm{Tg}$ levels are unreliable for use as TC markers during follow-up. Ideally, serum Tg assays should be performed in the same laboratory, since measured val- ues can differ among different clinical chemistry laboratories, even when international $\mathrm{Tg}$ standards are used $^{76}$. Tg levels above the following cut-off points indicate the presence of thyroid tissue, either normal (remnant) or malignant [even when a RAI WBS is negative], since $\mathrm{Tg}$ is only produced by thyroid tissue: $>0.5-1.0 \mathrm{ng} / \mathrm{ml}$, while on THST ${ }^{77} ;>8.0 \mathrm{ng} / \mathrm{ml}$ while off $\mathrm{TH}$ therapy ${ }^{78}$; and $>2.0 \mathrm{ng} / \mathrm{ml}$ after stimulation with recombinant human TSH (rhTSH; Thyrogen $\left.{ }^{\circledR}\right)^{79}$. It has to be noted that with newer, more reliable Tg assays, the cutoff Tg level of $8.0 \mathrm{ng} / \mathrm{ml}$ - assessed under hypothyroid conditions as an indicator of possible persistent thyroid tissue or recurrent disease - may be viewed by most authorities in the field as inordinately high. Indeed, we and others often see patients with biopsy-proven, low-volume persistent/recurrent PTC/ FTC who have Tg levels under hypothyroid conditions in the range of $2.0-8.0 \mathrm{ng} / \mathrm{ml}$. On the other hand, no systematic study exists to date assessing the validity of cutoff levels of serum Tg levels lower than $8.0 \mathrm{ng} /$ $\mathrm{ml}$ - measured under hypothyroid conditions - as an independent proof of evidence of clinically significant residual disease in PTC/FTC patients, especially when imaging studies for disease localization are unrevealing. Over the last decade, most algorithms for the diagnosis of residual/recurrent disease are based primarily on serum $\mathrm{Tg}$ analysis, as reflected in recently published follow-up guidelines by both U.S. ${ }^{80}$ and European $^{81}$ investigators.

In cases where residual/recurrent disease is suspected because of $\mathrm{Tg}$ levels above certain cutoff values (depending on the clinical circumstances), then imaging with other modalities (e.g. neck U/S, diagnostic RAI WBS, or ${ }^{18} \mathrm{~F}$-fluorodeoxyglucose positron emission tomography [FDG-PET]) is both appropriate and necessary for the detection of such clinically occult disease which, in fact, may be amenable to further therapy (surgery, RAI or other modalities).

Anti-Tg antibodies are found in $20 \%$ of patients with PTC/FTC. When anti-Tg antibodies are present, IRMA/ICMA-based Tg measurement methods are prone to underestimate the "true" serum Tg levels, thus increasing the possibility of missing metastatic disease. Additionally, serial serum anti-Tg antibody measurements usually parallel serial serum $\mathrm{Tg}$ measurements (by radioimmunoassay [RIA] techniques) ${ }^{82}$. However, it is debatable whether anti-Tg antibodies concentrations are clinically useful as tumor markers 


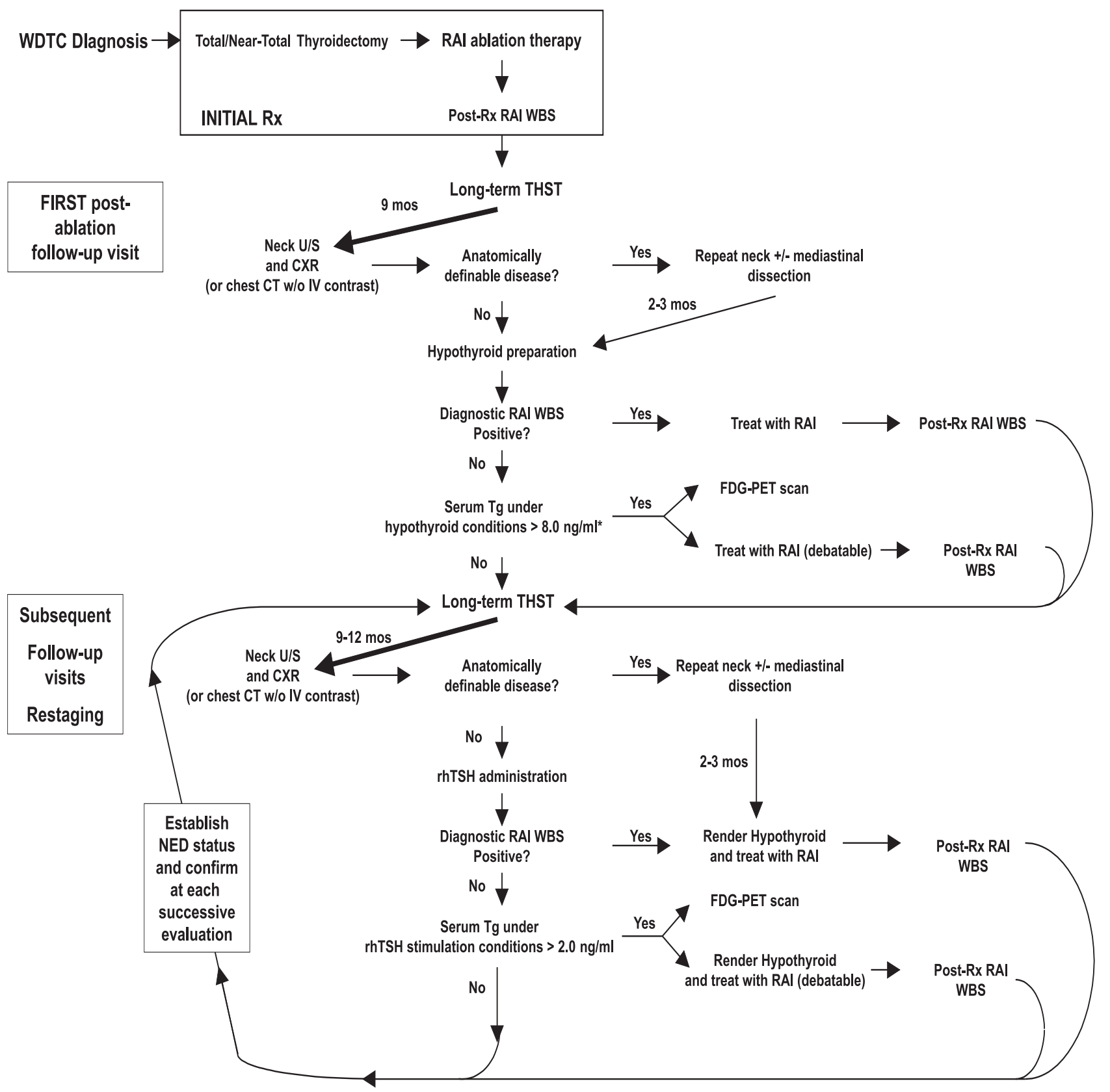

Figure 1. Algorithm for the follow-up of pediatric patients with well-differentiated thyroid carcinoma (WDTC) after total/near-total thyroidectomy and initial ${ }^{131} \mathrm{I}$ remnant ablation. In the proposed scheme, special emphasis is placed on the detection and eradication - whenever feasible - of persistent/recurrent metastatic disease in all patients who do not achieve no evidence of disease (NED) status. Different cutoff serum Tg values are used as corroborating evidence of residual/recurrent disease, depending on how TSH stimulation is achieved (thyroid hormone withdrawal vs. recombinant human thyrotropin [rhTSH] administration). For more details, refer to the text. Of note, RAI treatment for thyroid remnants can also be administered under stimulation with rhTSH. This is still considered an "off-label" use of rhTSH and should preferably be limited to tertiary center specialists with experience in the treatment of TC. Abbreviations: CT: computed tomography, CXR: chest X-ray, FDG-PET: ${ }^{18} \mathrm{~F}$-fluoro-deoxyglucose positron emission tomography, IV: intravenous, RAI: radioiodine $\left({ }^{131} \mathrm{I}\right)$, Rx: therapy, TH: thyroid hormone, THST: thyroid hormone suppressive therapy, U/S: ultrasonography, WBS: whole body scan, w/o: without.

$*$ : The serum Tg cutoff value of $8.0 \mathrm{ng} / \mathrm{ml}$ - when measured under hypothyroid conditions, as a surrogate indicator of the presence of persistent/recurrent disease after adequate primary therapy - may be inordinately high. In many cases, we proceed with extensive diagnostic imaging evaluation in patients with $\mathrm{Tg}$ levels in the range of $2.0-8.0 \mathrm{ng} / \mathrm{ml}$. When newer studies on this subject become available, it is highly likely that this cutoff $\mathrm{Tg}$ level will decrease significantly (in the range of $0.5-2.0 \mathrm{ng} / \mathrm{ml}$ ). 
for following individual TC patients over time. Qualitative and, more recently, quantitative methods of measuring Tg mRNA (extracted from peripheral whole blood samples) have been applied in cases wherein the presence of anti-Tg antibodies renders serum $\mathrm{Tg}$ measurements invalid ${ }^{83,84}$. However, these methods are not widely available, not always specific for TC, and not better - or cheaper - in a clinical practice setting than new Tg ICMAs/IRMAs. Consequently, their general use in TC patients is not yet advocat$\mathrm{ed}^{85}$. Another caveat in using serum Tg alone for monitoring disease status in PTC/FTC is the patient with dedifferentiated TC, whose tumor has lost the ability to synthesize and/or secrete $\mathrm{Tg}$, or secretes abnormal $\mathrm{Tg}$ molecules that cannot be detected by currently available Tg assays ${ }^{86,87}$.

\section{iv - b) RAI whole body scans}

The role of the RAI diagnostic WBS has changed dramatically with the introduction of rhTSH for monitoring of patients with PTC/FTC. Until recently, iatrogenic hypothyroidism achieved by withdrawal of $\mathrm{TH}$ therapy - with all the associated repercussions for the patient's quality of life - was required to proceed with a diagnostic RAI WBS. Hypothyroidism is no longer required, as iodine uptake by thyrocytes can be adequately stimulated by administration of exogenous rhTSH.

Traditionally, ${ }^{131}$ I has been used for the performance of diagnostic RAI WBSs. However, the administration of "tracer" doses (2-5 mCi; 74-185 MBq) of a $\beta$-particle emitter, such as ${ }^{131} \mathrm{I}$, for the performance of the scan has been claimed to induce "stunning" of the remnant tissue ${ }^{88,89}$, thus reducing the uptake of the subsequent therapeutic ${ }^{131}$ I dose. This stunning phenomenon seems to be more important in ${ }^{131}$ I ablation of thyroidal remnants, but some investigators believe that stunning occurs to a considerable degree in malignant thyroid cells as well, thus affecting the efficacy of ${ }^{131} \mathrm{I}$ administered for TC therapy ${ }^{90}$. In view of the above considerations, ${ }^{123} \mathrm{I}$ has recently been used for the performance of diagnostic RAI WBSs with success $^{91} .{ }^{123} \mathrm{I}$ is a pure $\gamma$-emitter RAI with much shorter half-life than ${ }^{131} \mathrm{I}$. Tracer doses of ${ }^{123} \mathrm{I}$ for scanning are in the range of $0.5-4 \mathrm{mCi}(18.5-148 \mathrm{MBq})$. The above notwithstanding, ${ }^{123} \mathrm{I}$ is more expensive than equal-activity doses of ${ }^{131} \mathrm{I}$, and there is limited experience with regard to the appropriate interpretation of ${ }^{123} \mathrm{I}$ scintigraphy for TC detection.
The above issues, i.e. convenience in patients' scheduling of follow-up visits and the possibility of stunning, have led many experts to dispute the necessity of performing a diagnostic RAI WBS altogether, at least in most low-risk TC cases, since an rhTSHstimulated serum Tg above $2.0 \mathrm{ng} / \mathrm{ml}$ can readily and reliably detect the presence of disease in patients with persistent TC. Indeed, in these patients, a diagnostic RAI WBS is positive in only $30-50 \%$ of cases ${ }^{92}$. Despite extensive experience reported by the MemorialSloan Kettering Cancer Center ([MSKCC], New York, $\mathrm{NY})^{93,94}$, there is no consensus as yet for the role of rhTSH in monitoring disease status in "high-risk" TC patients.

From the above, it is obvious that there are patients with detectable stimulated serum $\mathrm{Tg}$ (either after LT4 Rx discontinuation or post-rhTSH administration) and a negative diagnostic WBS. In cases such as these, we and others ${ }^{95}$ propose the use of non-RAIbased disease localizing modalities (U/S, computed tomography $[\mathrm{CT}]$, magnetic resonance imaging [MRI], bone imaging or FDG-PET) in efforts to identify disease amenable to surgical extirpation or other therapies (e.g. external beam radiotherapy; EBRT). In some of these cases, metastases are detected only after the administration of larger (therapeutic) RAI doses (usually in the range of $150-300 \mathrm{mCi}$; $5.6-11.1$ GBq) and subsequent performance of a "post-therapy" RAI WBS (usually performed 2-7 days after RAI therapy administration) ${ }^{96,97}$. In some of such cases, if the post-therapy RAI WBS is positive, then further RAI treatment(s) may be carefully considered aiming for induction of disease remission, or at least stabilization $^{98-100}$, although this approach remains controversial (101,102; J. Reynolds, NIH, Bethesda, MD; personal communication). The above notwithstanding, if the post-therapy RAI WBS is negative, the patient's disease is deemed non-avid to iodine and further RAI administration is of no clinical benefit ${ }^{36}$, or may in fact be harmful ${ }^{103,104}$.

It is important to emphasize at this point the role of an adequate preparation before a diagnostic RAI WBS and anticipated RAI therapy with depletion of the iodine body stores. This is achieved by implementing 2-3 weeks of low iodine diet prior to the administration of the RAI tracer dose, leading to increase the RAI uptake from thyroid tissue, which can in turn increase (up to 200\%) the radiation doses deposited 
therein (in cGy per $100 \mathrm{mCi}$ [3.7 GBq]) $)^{105,106}$.

The possibility of "false positive" RAI WBSs certainly exists but is rare. False positive WBSs can be caused by: body secretions, inflammatory processes, non-specific mediastinal or galbladder uptake, as well as, very rarely, RAI accumulation by non-thyroid malignancies ${ }^{107}$. Physiologic iodine uptake from the nasopharynx, salivary and sweat glands, mammary glands, stomach and genitourinary tract, or contamination of skin or hair can also give the impression of a positive scan. Diffuse hepatic uptake is commonly seen due to hepatic clearance of RAI-labeled Tg and other iodinated proteins (such as iodo-albumin), originating from thyroid remnants or metastatic disease ${ }^{108}$. Thus, low-level, diffuse hepatic RAI uptake does not signify the presence of liver metastases from PTC/ FTC, which are exceedingly rare $^{109}$.

\section{iv - c) Ultrasonography and chest radiography}

Neck U/S can accurately identify locoregional metastasis or tumor recurrence ${ }^{110}$. Serial neck U/S exams are recommended in most, but not all, consensus guidelines on TC follow-up. Additionally, chest X-ray has customarily been used in the periodic evaluation of patients with TC, although its sensitivity is at least $30 \%$ below that of a diagnostic RAI WBS (in the subgroup of patients with iodine-avid metastatic TC deposits to the lung) ${ }^{111}$. The presence of deposits demonstrable by simple chest radiograms portends a more grave prognosis vs. when such deposits are invisible ${ }^{112}$. Over the last 15 years, chest CT has been used for the diagnosis of micronodular or military TC spread or lymphangiitis pulmonis due to this malignancy, and has proven to be significantly more sensitive than simple chest radiograms ${ }^{113}$. On the other hand, in order for the chest CT to achieve its maximal sensitivity for disease detection, iodinated IV radiographic contrast administration is necessary. This precludes the use of this modality prior to the performance of diagnostic RAI WBSs or administration of RAI therapy, due to "cold" (stable) iodine contamination that abrogates RAI uptake by malignant thyrocytes. Stable iodine contamination after administration of IV contrast material can interfere with subsequent RAI uptake by TC deposits for up to 9 months, depending on the amount and type of contrast material administered ${ }^{114}$.

Finally, additional radiographic studies, such as CT, MRI, FDG-PET, ${ }^{99 \mathrm{~m}}$ Tc-MDP bone scan, bone X- ray metastatic survey, and ${ }^{111}$ In-pentetreotide scintigraphy $\left(\right.$ OctreoScan $\left.^{\circledR}\right)$, are not recommended routinely for follow-up of PTC/FTC patients, but have their utility in selected patients with residual/recurrent or metastatic disease ${ }^{115}$.

\section{v) Management of Residual/Recurrent PTC/ FTC after Initial Therapy}

Non-physiologic RAI uptake after primary TC therapy with T/NTT and successful thyroidal ablation correlates with the presence of functional TC. Most PTCs/FTCs accumulate enough RAI to allow effective therapy by ingestion of this radionuclide, but therapeutic success requires a high degree of stimulation by TSH, as well as the achievement of a very low whole body iodine status prior to therapy in order to increase the avidity of RAI uptake by TC cells. Therapeutic doses are generally continued to be given, as long as iodine-avid lesions persist - that show response to continuing therapy-or until a maximum cumulative lifetime RAI dose is reached.

In patients with evidence of non-resectable residual/recurrent TC after initial therapy, further RAI therapy may be given either empirically using "fixedsize" RAI therapy doses (150-200 mCi [5.55-7.4 GBq] per administration) - according to the University of Michigan protocol [reviewed by Beierwaltes ${ }^{116}$ ]- or "maximum tolerated"/“maximally safe" doses. In most centers, the upper threshold for empirically administered RAI therapy doses is $300 \mathrm{mCi}(11.1 \mathrm{GBq})$ per administration, although seminal studies from the MSKCC group had demonstrated that single administrations of RAI doses up to $750 \mathrm{mCi}$ could be safe in highly selected cases, at least with regard to acute RAIinduced toxicity ${ }^{117}$. These "maximally safe" doses are determined quantitatively by a pre-therapy study using RAI tracer with the method of "whole body and blood dosimetry". The latter procedure allows calculation of the expected whole body (WB) and whole blood/bone marrow acute radiation exposure from the administered RAI dose after estimating the radiation dose delivered to critical tissues [in rads/mCi (or rads/ $\mathrm{GBq}$ ) of administered RAI activity], as well as the expected retention of RAI in pulmonary metastases if any -, according to the MSKCC protocol developed in the mid-1960s ${ }^{118}$. We would like to emphasize here that what is ultimately important in RAI therapy of $\mathrm{TC}$ is the absorbed radiation dose (in cGy) to the tumor, and how it compares with absorbed radiation dos- 
es to the bone marrow and lungs so that a balance between benefit and risks can be achieved. Thus, it is these absorbed radiation doses to the tumor and critical host tissues that are biologically relevant, and not the activity of ${ }^{131} \mathrm{I}$ administered to the patient (measured in $\mathrm{mCi}$ [or $\mathrm{MBq}]$ ).

It is believed that dosimetry can minimize the risk of the two limiting acute complications of high-dose RAI therapy, i.e. bone marrow suppression and pulmonary fibrosis. The details of dosimetric protocols have been reviewed exhaustively in earlier publications ${ }^{89,119,120}$. Of note, dosimetry is not always predictive of the degree and timing of emergence of acute radiation side effects and cannot predict long-term stochastic side effects, such as development of secondary (radiation-induced) malignancies over time ${ }^{120}$. Finally, the availability of dosimetry is limited to only a few cancer centers internationally.

Lithium carbonate has been shown to increase iodine retention by PTC/FTC cells and, consequently, prolongs the period of intratumoral residence of RAI after therapy with RAI ${ }^{121}$. Thus, lithium can be useful as an adjunct to RAI therapy, at least in cases in which radioiodine turnover by the tumor is rapid. Although formal serial tumoral iodine uptake studies are required to document tumor turnover rates, lithium can also be used empirically in clinically aggressive, "highrisk" PTC/FTC cases. Lithium toxicity should be avoided by closely monitoring serial serum lithium levels, obtained on a daily or every-other-day basis, until the time of RAI therapy administration.

Limiting factors for RAI therapy are bone marrow toxicity (mainly leukopenia and thrombocytopenia) and radiation pneumonitis. Leukemia, small intestine, stomach, and bladder cancer (as well as perhaps breast cancer) are rare, yet serious, long-term potential complications of RAI therapy and tend to occur more frequently with cumulative life-time RAI doses above 1,200-1,500 mCi (44.4-55.5 GBq) $)^{122}$. Sialoadenitis with significant xerostomia and ageusia/dysgeusia, as well as transient oligospermia in males may occur with single RAI therapy doses in the range of 150-300 mCi (5.55-11.1 GBq), but are rarely permanent. Recently, amifostine has been used for the prevention of sialadenitis in a small number of cases receiving high-dose RAI with anecdotal success ${ }^{123}$.

Despite occasional achievement of extensive par- tial-or even complete - tumor responses after RAI therapy in patients with disseminated PTC/FTC, there is no statistical evidence that such therapy improves survival in "high-risk" patients, although it may decrease rate of disease progression. In fact, several cancer centers with treatment teams of conservative treatment philosophies (such as the Mayo Clinic, Rochester, MN) opt not to use further RAI therapies in patients with persistent TC once a cumulative RAI dose of $600-900 \mathrm{mCi}(22.2-33.3 \mathrm{GBq})$ has been reached, even in the presence of persistently positive previous post-therapy RAI WBSs and/or history of prior partial tumor response(s) to RAI, thus designating these patients as "RAI-resistant". Although we certainly agree that the majority of such patients will never be rendered disease-free by RAI alone, we also believe that in selected cases clinical "control" of symptomatic or life-threatening metastases can be achieved. Indeed, achievement of very long progression-free intervals has been documented in some cases after repeated courses of high-dose ("maximally safe") RAI therapy, with cumulative life-time RAI doses reaching 4,500 mCi (4.5 Ci; $166.5 \mathrm{GBq})(111,124$; H. Maxon; Hilton Head, SC; personal communication; K. Ain, Lexington, KY; personal communication)].

On the other hand, once TC cells cease concentrating RAI, further treatment presents a serious clinical dilemma. Approximately $30 \%$ of locoregional nonresectable recurrences from PTC/FTC fail to concentrate adequate amounts of RAI for their eradication by RAI alone ${ }^{125}$. The therapeutic options for patients harboring tumors that do not respond to RAI therapy are limited and generally ineffective with regard to disease eradication. Occasionally, however, significant long-term palliation can be achieved with judicious use of: palliative surgical debulking of recurrent disease; EBRT; chemotherapy; or a combination of the above modalities.

Extensive (debulking) metastasectomies in PTC/ FTC, especially in cases of RAI non-avid tumors, are justified in selected cases and may have a favorable short-term effect on prognosis and quality of life ${ }^{126}$. Electron beam EBRT is moderately effective as a local therapy directed usually against persistent/recurrent disease in the neck and upper mediastinum, CNS/ paraspinal structures and accessible bone sites. EBRT is employed when RAI cannot be used or when a local complication poses an imminent threat to limb or 
life [summarized in ${ }^{127}$. Heavy particle (e.g. proton) beam therapy for PTC/FTC, particularly in disease persisting in locations previously subjected to conventional EBRT, is currently under investigation ${ }^{128}$.

Chemotherapy is only minimally effective for the control of PTC/FTC and is considered only when other therapy options are impossible to implement or have been exhausted. Currently, the most effective single agent is doxorubicin (Adriamycin ${ }^{\circledR}$ ), given either alone or in combination with other agents. Other chemotherapy drugs that have been used in PTC/ FTC-either anecdotally or in small case series - include: cisplatin, cyclophosphamide, etoposide, carboplatin and, more recently, paclitaxel $\left(\mathrm{Taxol}^{\circledR}\right)$, all with generally modest results. In major cancer centers, including the NCI and MDACC, the combination of paclitaxel and carboplatin has been used for disease control in metastatic refractory $\mathrm{TC}$ with variable success, although formally reported data are lacking. Anecdotally, some patients who showed early responses to paclitaxel and became refractory to this agent may show responses to docetaxel (Taxotere ${ }^{\circledR}$ ) (M. Kies, MDACC, Houston, TX; personal communication). EBRT combined with either low-dose doxorubicin ( \pm cisplatin) or paclitaxel ( \pm carboplatin) (used as "radiosensitizers") can occasionally eradicate locally invasive, inoperable TC deposits that threaten the larynx, trachea, esophagus or other structures of the thoracic inlet, but will not prevent the subsequent development of distant metastases ${ }^{129}$. The latter, of course, eventually become limiting for survival ${ }^{130}$.

Finally, retinoic acid analogs, such as high-dose oral isotretinoin, have been used anecdotally aiming at "redifferentiation" of metastatic PTC/FTC deposits, i.e. in efforts to induce the accumulation and retention of iodine by the TC cell, thus allowing for the re-introduction of high-dose RAI therapies for disease con$\operatorname{trol}^{131,132}$. Heretofore, this aim has remained elusive, although new compounds, such as histone deacetylase inhibitors ${ }^{133}$, and other transcriptional modulators, such as valproate ${ }^{134}$, are under investigation.

\section{CONTROVERSIES IN ANAPLASTIC TC (ATC): PATHOLOGY AND PROGNOSIS}

ATC represents $8-10 \%$ of $\mathrm{TCs}^{34}$. This is an undifferentiated carcinoma, thought to arise from "transformation" of a long-standing PTC (or, more rarely,
FTC or nodular goiter) in $\sim 50 \%$ of cases ${ }^{135}$. There are four major histological subtypes of ATC: giant-, spindle-, squamoid-, clear-cell variants. However, the final clinical outcome in patients with this malignancy is the same regardless of its histologic subtype ${ }^{136}$. The previously described subtype of "small-cell" ATC should no longer be used, since most of these cases were in fact thyroid lymphomas, poorly differentiated MTCs or metastases to the thyroid from other primary malignancies ${ }^{137}$. ATCs also usually lose their ability to produce/secrete $\mathrm{Tg}$ and, hence, $\mathrm{Tg}$ cannot be used as a tumor marker in this malignancy ${ }^{138}$. At the time of initial diagnosis, $50 \%$ of ATC patients have distant metastases - mainly in the lungs, bones, liver, and brain/intraspinal; paraspinal tissues - , whilst another $25 \%$ of patients develop distant deposits during the course of the disease ${ }^{139}$. The prognosis is dismal, with most patients succumbing to the disease within a few months after initial diagnosis because of either locoregional disease - and associated complications (e.g. airway obstruction) - or galloping distant metastases $^{139}$.

\section{CONTROVERSIES IN ATC MANAGEMENT}

ATC is almost uniformly fatal. Hence, in almost all cases the only aim of treatment is palliation. If there is no extracervical disease and functional surgical excision of the primary tumor site is feasible, then $\mathrm{T} /$ NTT with bilateral modified radical neck dissections (MRNDs) is recommended ${ }^{140}$. EBRT can result in local disease "control", although recurrences occur frequently ${ }^{141}$. Systemic chemotherapy has been disappointing in altering the fatal outcome of the disease. Combination chemotherapy with doxorubicin and cisplatin + bleomycin showed only minimal improvement in clinical response vs. doxorubicin alone ${ }^{142,143}$. In a recent trial, paclitaxel resulted in a 53\% combined (partial and minimal) response rate; there was no patient with complete response to paclitaxel, and the partial responses were relatively short-lived ${ }^{144}$. Newer taxanes, such as docetaxel $\left(\right.$ Taxotere $^{\circledR}$ ), as well as epothilones, may show promise in ATC therapy ${ }^{145}$, although they have not been studied formally in this malignancy. Of note, aggressive cytotoxic therapy with a taxane and cisplatinum (or carboplatin) combination usually mandates rescue with hematopoietic growth factor administration due to potentially severe and/or prolonged therapy-induced cytopenias ${ }^{146}$, and 
should be reserved for younger and healthier patients with metastatic ATC. Currently, the use of combination therapies (radiation, chemotherapy and aggressive surgical intervention) should be considered the "standard of care" for patients with resectable ATC ${ }^{147}$.

\section{CONTROVERSIES IN MEDULLARY TC (MTC): PATHOLOGY AND PROGNOSIS}

MTC represents $6 \%-8 \%$ of $\mathrm{TCs}^{34}$. This malignancy is derived from the calcitonin-producing parafollicular (or C-) cells, which are of neuroectodermal origin. Hence, MTCs are not iodine-avid and their growth is not TSH-dependent. Furthermore, these malignancies do not produce/secrete Tg. MTCs overall show more malignant potential than "ordinary" PTCs or "minimally-invasive" FTCs. MTC is believed to develop through a pre-malignant stage of C-cell hyperplasia $(\mathrm{CCH})$, subsequently leading to the formation of "micro-MTC", and eventually macroscopic malignancy ${ }^{148}$.

It is important for the clinician to keep in mind that MTC can be associated with paraneoplastic manifestations due to the production of various substances by the tumor (with corresponding clinical syndromes in brackets), including: 5-HT (5-hydroxytryptamine or serotonin) [flushing, carcinoid syndrome] ${ }^{149}$; adrenocorticotropin $(\mathrm{ACTH})$ /corticotropin releasing hormone (CRH) [ectopic Cushing's syndrome] ${ }^{150,151}$; prostaglandins [flushing, diarrhea]; brady- and tachykinins [flushing, hypotension]; and vasoactive intestinal peptide (VIP) [watery diarrhea-hypokalemia-achlorhydria [WDHA] syndrome] ${ }^{152}$.

Calcitonin secretion by the tumor renders this neuropeptide a useful marker for MTC at the time of initial diagnosis (with the limitations discussed in the section of diagnostic evaluation of thyroid nodules) and, more importantly, during follow-up after initial therapy. Plasma calcitonin levels correlate directly with tumor mass in that an approximately spherical MTC lesion of $1.0 \mathrm{~cm}$ in diameter corresponds to a plasma calcitonin level of $\sim 1,000 \mathrm{pg} / \mathrm{ml}^{153}$. The above notwithstanding, some MTCs are partially dedifferentiated, thus having diminished or completely lost ability of calcitonin secretion; in these tumors, plasma calcitonin cannot be used as a reliable tumor marker ${ }^{154}$. On the other hand, almost all MTCs retain their ability to express and secrete carcinoembryonic antigen
(CEA) and, hence, even in tumors that have lost their calcitonin expression capacity, serum CEA can be used as a surrogate marker of tumor burden ${ }^{155}$. The role of chromogranin-A (CG-A) in the diagnosis of residual/ recurrent MTC remains under investigation ${ }^{156}$.

Sporadic MTC accounts for $\sim 80 \%$ of all MTC cases, the remaining $20 \%$ of cases developing in the realm of one of three familial syndromes with autosomal dominant inheritance pattern, often associated with other endocrine neoplasms. These syndromes are: Multiple Endocrine Neoplasia (MEN) types -2A and $-2 \mathrm{~B}$, and familial MTC (FMTC) ${ }^{95,157}$. Patients with MTCs occurring in a familial pattern universally harbor germline activating mutations of the RET protooncogene. In these syndromes, there is definite correlation between the clinical phenotype and the site (codon) of the mutation along the RET oncogene sequence $^{158}$. On the other hand, there is variable biological aggressiveness of MTCs occurring among family members who carry the very same RET mutation, a fact suggesting that other variables (both genetic and environmental) are important in determining malignant potential in $\mathrm{MTC}^{159}$. It is important to screen for RET mutations in all MTC cases, even those in which the tumor is "apparently sporadic", since $\sim 6 \%$ of patients harboring these "apparently sporadic" tumors are found to carry germline RET mutations; this has important implications for the patients and their families ${ }^{160}$. Patients with MTC who undergo genetic screening for RET oncogene mutations should always undergo genetic counseling prior to consenting for such testing, due to the social, familial, psychological, and potentially financial implications of positive genetic testing results ${ }^{161}$.

Regarding prognosis in MTC, patients under 40 years of age at the time of diagnosis have a 10-year survival of $\sim 75 \%$, as opposed to $\sim 50 \%$ for those above 40 years of age at the time of diagnosis ${ }^{162}$. Of note, the familial syndromes associated with MTC show significant differences in aggressiveness of the malignancies that develop in their context. The following order of MTC aggressiveness has been observed ${ }^{163}$ : MEN2B $>>$ MEN2A $>$ FMTC

\section{MTC: CONTROVERSIES IN ITS MANAGEMENT AND FOLLOW-UP}

MTC remains a predominantly surgical disease. T/ 
NTT and central neck compartment dissection should be done in all cases, with consideration to be given to ipsilateral MRND and/or mediastinal dissection ${ }^{162}$. Bilateral neck dissections are recommended for all familial cases, as well as multifocal, apparently sporadic $\mathrm{MTC}^{162}$. For members of families of MEN2 who are proven to be carriers of RET gene mutation, prophylactic thyroidectomy is recommended. The timing of the surgery is controversial, but it depends on the actual codon of the RET gene where the mutation is localized ${ }^{165}$ :

- Children with MEN2B and/or RET codon 883, 918 or 922 mutations are classified as having the highest risk for aggressive MTC development ("level 3 risk"), and should have T/NTT within the first 6 months - preferably within the first month - of life.

- Children with RET codon 611, 618, 620 or 634 mutations are classified as having a moderately high risk for aggressive MTC development ("level 2 risk"), and should have T/NTT performed before the age of 5 .

- Children with RET codon 609, 768, 790, 791804 and 891 mutations are classified as having the least high risk of developing aggressive MTC ("level 1 risk"). There is little consensus on the management of patients with these mutations. Some advocate T/NTT by the age of 5 . Others suggest that thyroidectomy by age 10 is appropriate, while yet other clinicians recommend periodic pentagastrin-stimulated calcitonin testing only, withholding surgery until the first occurrence of an abnormal stimulated calcitonin result.

Postoperative EBRT should be offered to patients with high risk of recurrence in the thyroid bed, as well as those who present with cervical, supraclavicular or mediastinal lymphadenopathy ${ }^{166}$. Of note, there is no role of RAI ablative therapy in the postoperative management of MTC. Peripheral levels of calcitonin and CEA are used for monitoring disease activity after the initial operation. Patients with persistently elevated - or increasing - calcitonin levels harbor residual or recurrent/metastatic MTC and, in these cases, additional imaging should be performed for localization of the disease deposits, leading to potential further surgical treatment. Imaging is done with conventional modalities, such as neck U/S and CT/MRI. Additional imaging modalities, such as scintigraphy with ${ }^{111}$ In-pentetreotide (OctreoScan $\left.{ }^{\circledR}\right){ }^{167},{ }^{131} \mathrm{I}$ - (or ${ }^{123} \mathrm{I}$-) meta-iodobenzylguanidine (MIBG) $)^{168},{ }^{131} \mathrm{I}$ - or ${ }^{90} \mathrm{Y}$-labeled anti-CEA antibodies ${ }^{169}$, or positron emission tomography (PET) with ${ }^{18} \mathrm{~F}$-fluoro-deoxyglucose $(\mathrm{FDG})^{170}$ - or fluoro-dopamine ${ }^{171}-$ can be used in selected cases. Additionally, selective venous catheterization of the neck/mediastinal venous systems can be useful in localizing disease ${ }^{172}$. The use of MTC-seeking radionuclides for imaging has led to their consideration as potential therapeutic agents, although the current experience with ${ }^{90} \mathrm{Y}$-labeled anti-CEA antibodies or ${ }^{131}$ I-MIBG is limited to a few cancer centers ${ }^{168,173}$.

\section{RARE THYROID TUMORS: CONTROVERSIES IN THEIR DIAGNOSIS AND MANAGEMENT}

In addition to the above categories of TC, rarely, other tumorous conditions also occur that either originate in or extend to the thyroid gland ${ }^{171}$. These are as follows:

- Mucoepidermoid TC (with or without peritumoral sclerosis and eosinophilic infiltrates) ${ }^{175}$.

- Thyroid lymphoma. This is usually a non-Hodgkin's T-lymphocyte large-cell immunoblastic lymphoma; more rarely, thyroid lymphomas can be low-grade "MALTomas". There is definite association of the development of thyroid lymphoma with long-standing Hashimoto's thyroiditis. Thyroid lymphoma occurs primary in the elderly ${ }^{176}$.

- Sarcoma (fibro-, lympho-, lipo-, carcinosarcoma, Kaposi sarcoma $)^{177-180}$.

- Hemangioendothelioma; Angiosarcoma ${ }^{181,182}$.

- Thyroid teratoma. (This is usually a benign tumor in childhood and adolescence, yet it shows highly malignant behavior in adults.) $)^{183}$

- Primary thyroid thymoma ${ }^{184}$.

- Plasmocytoma ${ }^{185}$.

- Langerhans'-cell histiocytosis (LCH ${ }^{186}$.

- Rosai-Dorfman disease (sinus histiocytosis with massive lymphadenopathy $)^{187}$.

- Metastatic tumors to the thyroid (metastases from: lung, breast, kidney, colon, pancreas, ovary, esophagus, bladder, vaginal primary carcinoma, metastases from melanoma, and metastases from car- 
cinoma of unknown primary [CUP] $)^{188-190}$.

- Malignant neuroendocrine thyroid tumors, including chemodectomas and paragangliomas ${ }^{191}$.

The prognosis of these rare tumors of the thyroid gland remains only partially known, primarily due to the rarity of the above entities. Similarly, there are no set treatment guidelines for these entities. When we are confronted with patients having these rare thyroid tumors, we are acutely reminded of the need for the application of an extended differential diagnosis, especially in cases of thyroid nodules with unusual or atypical cytopathologic or histopathologic features, and subsequent need for referral to a tertiary/referral cancer center.

- Finally, we would like to mention the entity of malignant struma ovarii (MSO). This is a rare teratomatous tumor that originates from thyroid cellular elements in the ovary. Malignant transformation of formerly benign strumae ovarii to MSO most commonly are associated with an FTC-like phenotype, although, rarely MSOs are encountered with PTC-like histologic differentiation. The pattern of metastases from MSO primaries is different from that of TCs originating in the thyroid, due to the site of origin of the malignancy. MSOs frequently demonstrate lymphatic spread to the abdominal lymph nodes, peritoneum, and liver ${ }^{192}$. Treatment in the absence of widely metastatic disease consists of ipsilateral salpingo-oophorectomy and extensive regional node dissection. If metastatic disease exists at presentation, then local surgery should be followed by T/NTT, and administration of high-dose RAI therapy under hypothyroid conditions ${ }^{193}$.

\section{ACKNOWLEDGEMENTS}

We would like to thank Drs. Rena VassilopoulouSellin, Steven G. Waguespack, and Adel El-Naggar, The University of Texas - M. D. Anderson Cancer Center, Houston, Texas, Dr. Tito Fojo, NCI, National Institutes of Health, Bethesda, Maryland, Dr. Kenneth D. Burman, Washington Hospital Center, Washington, D.C., as well as Dr. Andzej Kudelka, Pfizer Inc., New London, CT, for helpful discussions and instructive comments and suggestions. Dr. Sarlis would also like to express his most sincere gratitude to Dr. Jacob Robbins, Scientist Emeritus, NIDDK, Nation- al Institutes of Health, Bethesda, Maryland, who has been the source of continuous inspiration and guidance through many years, and to whom this monograph is dedicated.

\section{REFERENCES}

1. Vander JB, Gaston EA, Dawber TR, 1968 The significance of nontoxic thyroid nodules. Final report of a 15year study of the incidence of thyroid malignancy. Ann Intern Med 69: 537-540.

2. Tunbridge WM, Evered DC, Hall R, et al, 1977 The spectrum of thyroid disease in a community: the Whickham survey. Clin Endocrinol 7: 481-493.

3. Mortensen JD, Woolner LB, Bennett WA, 1955 Gross and microscopic findings in clinically normal thyroid glands. J Clin Endocrinol Metab 15: 1270-1280.

4. Horlocker TT, Hay JE, James EM, Reading CC, Charboneau JE 1985 Prevalence of incidental nodular thyroid disease detected during high resolution parathyroid ultrasonography. In: Medeiros-Neto G, Gaitan E (eds) Frontiers in Thyroidology, Plenum Medical Publication, New York; pp, 1309-1312.

5. Stark DD, Clark OH, Gooding GA, Moss AA, 1983 Highresolution ultrasonography and computed tomography of thyroid lesions in patients with hyperparathyroidism. Surgery $94: 863-868$.

6. Tan GH, Gharib H, Reading CC, 1995 Solitary thyroid nodule. Comparison between palpation and ultrasonography. Arch Intern Med 155: 2418-2423.

7. Hagag P, Strauss S, Weiss M, 1998 Role of ultrasoundguided fine-needle aspiration biopsy in evaluation of nonpalpable thyroid nodules. Thyroid 8: 989-995.

8. Leenhardt L, Hejblum G, Franc B,et al, 1999 Indications and limits of ultrasound-guided cytology in the management of nonpalpable thyroid nodules. J Clin Endocrinol Metab 84: 24-28.

9. Wang C, Crapo LM, 1997 The epidemiology of thyroid disease and implications for screening. Endocrinol Metab Clin North Am 26: 189-218.

10. Ross DS, 2002 Nonpalpable thyroid nodules - managing an epidemic. J Clin Endocrinol Metab 87: 1938-1940.

11. Martinez-Tello FJ, Martinez-Cabruja R, Fernandez-Martin J, Lasso-Oria C, Ballestin-Carcavilla C, 1993 Occult carcinoma of the thyroid. A systematic autopsy study from Spain of two series performed with two different methods. Cancer 71: 4022-4029.

12. Marqusee E, Benson CB, Frates MC, et al, 2000 Usefulness of ultrasonography in the management of nodular thyroid disease. Ann Intern Med 133: 696-700.

13. Woeber KA, 1999 The year in review: the thyroid. Ann Intern Med 131: 959-962.

14. Papini E, Guglielmi R, Bianchini A,et al, 2002 Risk of malignancy in nonpalpable thyroid nodules: predictive value of ultrasound and color-Doppler features. J Clin Endocrinol Metab 87: 1941-1946.

15. Feld S, and the Thyroid Nodule Task Force, 1996 AACE 
Clinical Practice Guidelines for the Diagnosis and Management of Thyroid Nodules. Endocr Practice 2: 78-84.

16. Wu Y, Wang JD, Yuan JD, Wang HS, 1995 Papillary microcancer of the thyroid. Ann Chir 49: 959-962.

17. Varcus F, Peix JL, Berger N, Bordos D, 2002 Thyroid scintigraphy: its place in preoperative diagnosis of thyroid nodules? Ann Chir 127: 685-689.

18. Harach HR, Sanchez SS, Williams ED, 2002 Pathology of the autonomously functioning (hot) thyroid nodule. Ann Diagn Pathol 6: 10-19.

19. Als C, Gedeon P, Rosler H, Minder C, Netzer P, Laissue JA, 2002 Survival analysis of 19 patients with toxic thyroid carcinoma. J Clin Endocrinol Metab 87: 4122-4127.

20. Hodak SP, Burman KD, 2004 The calcitonin conundrum - is it time for routine measurement of serum calcitonin in patients with thyroid nodules? J Clin Endocrinol Metab 89: 511-514.

21. Niccoli P, Wion-Barbot N, Caron P, et al, 1997 Interest of routine measurement of serum calcitonin: study in a large series of thyroidectomized patients. The French Medullary Study Group. J Clin Endocrinol Metab 82: 338341.

22. Hahm JR, Lee MS, Min YK, et al, 2001 Routine measurement of serum calcitonin is useful for early detection of medullary thyroid carcinoma in patients with nodular thyroid diseases. Thyroid 11: 73-80.

23. Vierhapper H, Raber W, Bieglmayer C, Kaserer K, Weinhausl A, Niederle B, 1997 Routine measurement of plasma calcitonin in nodular thyroid diseases. J Clin Endocrinol Metab 82: 1589-1593.

24. Rieu M, Lame MC, Richard A, et al, 1995 Prevalence of sporadic medullary thyroid carcinoma: the importance of routine measurement of serum calcitonin in the diagnostic evaluation of thyroid nodules. Clin Endocrinol 42: 453460 .

25. Karanikas G, Moameni A, Poetzi C, et al, 2004 Frequency and relevance of elevated calcitonin levels in patients with neoplastic and nonneoplastic thyroid disease and in healthy subjects. J Clin Endocrinol Metab 89: 515-519.

26. Gharib H, 1994 Fine-needle aspiration biopsy of thyroid nodules: advantages, limitations, and effect. Mayo Clin Proc 69: 44-49.

27. Gharib H, Goellner JR, 1993 Fine-needle aspiration biopsy of the thyroid: an appraisal. Ann Intern Med 118: 282-289.

28. Burch HB, 1995 Evaluation and management of the solid thyroid nodule. Endocrinol Metab Clin North Am 24: 663710.

29. Atkinson BF, 1993 Fine needle aspiration of the thyroid. Monogr Pathol 166-199.

30. Oertel YC, 1996 Fine-needle aspiration and the diagnosis of thyroid cancer. Endocrinol Metab Clin North Am 25: 69-91.

31. Gharib H, 1997 Changing concepts in the diagnosis and management of thyroid nodules. Endocrinol Metab Clin North Am 26: 777-800.

32. Udelsman R, Westra WH, Donovan PI, Sohn TA, Cameron JL, 2001 Randomized prospective evaluation of frozen-section analysis for follicular neoplasms of the thyroid. Ann Surg 233: 716-722.

33. Mulcahy MM, Cohen JI, Anderson PE, Ditamasso J, Schmidt W, 1998 Relative accuracy of fine-needle aspiration and frozen section in the diagnosis of well-differentiated thyroid cancer. Laryngoscope 108: 494-496.

34. Hundahl SA, Fleming ID, Fremgen AM, Menck HR, 1998 A National Cancer Data Base report on 53,856 cases of thyroid carcinoma treated in the U.S., 1985-1995. Cancer 83: $2638-2648$

35. Nasir A, Chaudhry AZ, Gillespie J, Kaiser HE, 2000 Papillary microcarcinoma of the thyroid: a clinico-pathologic and prognostic review. In Vivo 14: 367-376.

36. Mazzaferri EL, Massoll N, 2002 Management of papillary and follicular (differentiated) thyroid cancer: new paradigms using recombinant human thyrotropin. Endocr Relat Cancer 9: 227-247.

37. Chan JK, 1990 Papillary carcinoma of thyroid: classical and variants. Histol Histopathol 5: 241-257.

38. Filie AC, Chiesa A, Bryant BR, Merino MJ, Sobel ME, Abati A, 1999 The Tall cell variant of papillary carcinoma of the thyroid: cytologic features and loss of heterozygosity of metastatic and/or recurrent neoplasms and primary neoplasms. Cancer 87: 238-242.

39. Chow SM, Chan JK, Law SC, et al, 2003 Diffuse sclerosing variant of papillary thyroid carcinoma - clinical features and outcome. Eur J Surg Oncol 29: 446-449.

40. Zagar I, Vidergar-Kralj B, Schwarzbartl-Pevec AA, Pompe F, 2003 Columnar cell thyroid carcinoma - diagnostic dilemmas and pitfalls. Nucl Med Rev Cent East Eur 6: 155-158.

41. Nikiforov YE, Erickson LA, Nikiforova MN, Caudill CM, Lloyd RV, 2001 Solid variant of papillary thyroid carcinoma: incidence, clinical-pathologic characteristics, molecular analysis, and biologic behavior. Am J Surg Pathol 25: 1478-1484.

42. Xu B, Yoshimoto K, Miyauchi A, et al, 2003 Cribriformmorular variant of papillary thyroid carcinoma: a pathological and molecular genetic study with evidence of frequent somatic mutations in exon 3 of the beta-catenin gene. J Pathol 199: 58-67.

43. Dahia PL, Marsh DJ, Zheng Z et al, 1997 Somatic deletions and mutations in the Cowden disease gene, PTEN, in sporadic thyroid tumors. Cancer Res 57: 4710-4713.

44. Yamamoto M, Hoshino H, Onizuka T, Ichikawa M, Kawakubo A, Hayakawa S, 1992 Thyroid papillary adenocarcinoma in a woman with Peutz-Jeghers syndrome. Intern Med 31: 1117-1119.

45. Reed MW, Harris SC, Quayle AR, Talbot CH, 1990 The association between thyroid neoplasia and intestinal polyps. Ann R Coll Surg Engl 72: 357-359.

46. Stergiopoulos SG, Stratakis CA, 2003 Human tumors associated with Carney complex and germline PRKAR1A mutations: a protein kinase A disease. FEBS Lett 546: 59-64.

47. Orsenigo E, Beretta E, Gini P,et al, 2003 A report of six cases of familial papillary thyroid cancer. Eur J Surg Oncol 29: 185-187. 
48. Uchino S, Noguchi S, Kawamoto H, Yamashita H, Watanabe S, Shuto S, 2002 Familial nonmedullary thyroid carcinoma characterized by multifocality and a high recurrence rate in a large study population. World J Surg 26: 897-902.

49. Hemli JM, Barakate MS, Appleberg M, Delbridge LW, 2001 Papillary carcinoma of the thyroid arising in struma ovari - report of a case and review of management guidelines. Gynecol Endocrinol 15: 243-247.

50. Grebe SK, Hay ID, 1995 Follicular thyroid cancer. Endocrinol Metab Clin North Am 24: 761-801.

51. Lin JD, Jeng LB, Chao TC, Weng HF, Huang HS, 1996 Surgical treatment of papillary and follicular thyroid carcinoma. Int Surg 81: 61-66.

52. Lopez-Penabad L, Chiu AC, Hoff AO, et al, 2003 Prognostic factors in patients with Hurthle cell neoplasms of the thyroid. Cancer 97: 1186-1194.

53. Palestini N, Papotti M, Durando R, Fortunato MA, 1993 Poorly differentiated "insular" carcinoma of the thyroid: long-term survival. Minerva Chir 48: 1301-1305.

54. Bal C, Padhy AK, Panda S, Kumar L, Basu AK, 1993 "Insular" carcinoma of thyroid. A subset of anaplastic thyroid malignancy with a less aggressive clinical course. Clin Nucl Med 18: 1056-1058.

55. Hewavisenthi SJ, Ariyarathne J, Gunawardena PA, 2000 Mixed medullary follicular carcinoma - an unusual thyroid neoplasm. Ceylon Med J 45: 34-35.

56. Bhansali A, Jain V, Rajwanshi A, Lodha S, Dash RJ, 1999 Follicular carcinoma in a functioning struma ovarii. Postgrad Med J 75: 617-618.

57. Sarlis NJ, Gourgiotis L, Filie AC, 2002 Misclassification of cytologic diagnoses in patients with follicular lesions or follicular neoplasms of the thyroid gland: implications for patient care and clinical research. Cancer Cytopathol 96: 323-324

58. Basolo F, Caligo MA, Pinchera A, et al, 2000 Cyclin D1 overexpression in thyroid carcinomas: relation with clinico-pathological parameters, retinoblastoma gene product, and Ki67 labeling index. Thyroid 10: 741-746.

59. Kovacs RB, Foldes J, Winkler G, Bodo M, Sapi Z, 2003 The investigation of galectin-3 in diseases of the thyroid gland. Eur J Endocrinol 149: 449-453.

60. Greene FL, Page DL, Fleming ID, et al (eds) 2002 AJCC Cancer Staging Manual. Springer Publication Inc, New York, NY.

61. Sobin LH, Wittekind Ch 2002 TNM Classification of malignant tumours. In: Wiley-Liss Publication Inc, New York, NY

62. Sherman SI, Brierley JD, Sperling M, et al, 1998 Prospective multicenter study of thyrois carcinoma treatment: initial analysis of staging and outcome. National Thyroid Cancer Treatment Cooperative Study Registry Group. Cancer 83: 1012-1021.

63. Cooper DS, Specker B, Ho M, et al, 1998 Thyrotropin suppression and disease progression in patients with differentiated thyroid cancer: results from the National Thyroid Cancer Treatment Cooperative Registry. Thyroid 8: 737-744.
64. Mazzaferri EL, 1999 NCCN thyroid carcinoma practice guidelines. Proceedings of the National Comprehensive Cancer Network. Oncology 13: 391S-442S.

65. British Thyroid Association, 2002 Guidelines for the management of differentiated thyroid cancer in adults. http:/ /www.british-thyroid-association.org/guidelines.htm

66. Hay ID, Grant CS, Taylor WF, McConahey WM, 1987 Ipsilateral lobectomy versus bilateral lobar resection in papillary thyroid carcinoma: a retrospective analysis of surgical outcome using a novel prognostic scoring system. Surgery 102: 1088-1095.

67. Mazzaferri EL, Kloos RT, 2001 Clinical review 128: Current approaches to primary therapy for papillary and follicular thyroid cancer. J Clin Endocrinol Metab 86: 14471463.

68. Scheumann GF, Seeliger H, Musholt TJ, et al, 1996 Completion thyroidectomy in 131 patients with differentiated thyroid carcinoma. Eur J Surg 162: 677-684.

69. Miccoli P, Antonelli A, Spinelli C, Ferdeghini M, Fallahi P, Baschieri L, 1998 Completion total thyroidectomy in children with thyroid cancer secondary to the Chernobyl accident. Arch Surg 133: 89-93.

70. Ladenson PW, Pacini F, Schlumberger M, et al 2004 Clinical Trial Symposium. Proc $86^{\text {th }}$ Ann Mtg Endo Soc, New Orelans, LA, Abstract: Suppl: 35-41.

71. Mazzaferri EL, Jhiang SM, 1994 Long-term impact of initial surgical and medical therapy on papillary and follicular thyroid cancer. Am J Med 97: 418-428.

72. McGriff NJ, Csako G, Gourgiotis L, Lori CG, Pucino F, Sarlis NJ, 2002 Effects of thyroid hormone suppression therapy on adverse clinical outcomes in thyroid cancer. Ann Med 34: 554-564.

73. Burmeister LA, Goumaz MO, Mariash CN, Oppenheimer JH, 1992 Levothyroxine dose requirements for thyrotropin suppression in the treatment of differentiated thyroid cancer. J Clin Endocrinol Metab 75: 344-350.

74. Bartalena L, Martino E, Pacchiarotti A, et al, 1987 Factors affecting suppression of endogenous thyrotropin secretion by thyroxine treatment: retrospective analysis in athyreotic and goitrous patients. J Clin Endocrinol Metab 64: 849-855.

75. Pujol P, Daures JP, Nsakala N, Baldet L, Bringer J, Jaffiol C, 1996 Degree of thyrotropin suppression as a prognostic determinant in differentiated thyroid cancer. J Clin Endocrinol Metab 81: 4318-4323.

76. Spencer CA, Takeuchi M, Kazarosyan M, 1996 Current status and performance goals for serum thyroglobulin assays. Clin Chem 42: 164-173.

77. Cailleux AF, Baudin E, Travagli JP, Ricard M, Schlumberger M, 2000 Is diagnostic iodine-131 scanning useful after total thyroid ablation for differentiated thyroid cancer? J Clin Endocrinol Metab 85: 175-178.

78. Ozata M, Suzuki S, Miyamoto T, Liu RT, Fierro-Renoy F, DeGroot LJ, 1994 Serum thyroglobulin in the followup of patients with treated differentiated thyroid cancer. J Clin Endocrinol Metab 79: 98-105.

79. Haugen BR, Pacini F, Reiners C, et al, 1999 A comparison of recombinant human thyrotropin and thyroid hor- 
mone withdrawal for the detection of thyroid remnant or cancer. J Clin Endocrinol Metab 84: 3877-3885.

80. Mazzaferri EL, Robbins RJ, Spencer CA, et al, 2003 A consensus report of the role of serum thyroglobulin as a monitoring method for low-risk patients with papillary thyroid carcinoma. J Clin Endocrinol Metab 88: 14331441.

81. Schlumberger M, Berg G, Cohen O, et al, 2004 Followup of low-risk patients with differentiated thyroid carcinoma: a European perspective. Eur J Endocrinol 150: 105112.

82. Spencer CA, Takeuchi M, Kazarosyan M, et al, 1998 Serum thyroglobulin autoantibodies: prevalence, influence on serum thyroglobulin measurement, and prognostic significance in patients with differentiated thyroid carcinoma. J Clin Endocrinol Metab 83: 1121-1127.

83. Grammatopoulos D, Elliott Y, Smith SC, et al, 2003 Measurement of thyroglobulin mRNA in peripheral blood as an adjunctive test for monitoring thyroid cancer. Mol Pathol 56: 162-166.

84. Ringel MD, Balducci-Silano PL, Anderson JS, et al, 1999 Quantitative reverse transcription-polymerase chain reaction of circulating thyroglobulin messenger ribonucleic acid for monitoring patients with thyroid carcinoma. J Clin Endocrinol Metab 84: 4037-4042.

85. Ringel MD, 2004 Molecular detection of thyroid cancer: differentiating "signal" and "noise" in clinical assays. J Clin Endocrinol Metab 89: 29-32.

86. Westbury C, Vini L, Fisher C, Harmer C, 2000 Recurrent differentiated thyroid cancer without elevation of serum thyroglobulin. Thyroid 10: 171-176.

87. Sinadinovic J, Cvejic D, Savin S, Jancic-Zuguricas M, Micic JV, 1992 Altered terminal glycosylation of thyroglobulin in papillary thyroid carcinoma. Exp Clin Endocrinol 100: 124-128.

88. Park HM, Perkins OW, Edmondson JW, Schnute RB, Manatunga A, 1994 Influence of diagnostic radioiodines on the uptake of ablative dose of iodine-131. Thyroid 4: 49-54.

89. Reynolds JC, Robbins J, 1997 The changing role of radioiodine in the management of differentiated thyroid cancer. Semin Nucl Med 27: 152-164.

90. Morris LF, Waxman AD, Braunstein GD, 2003 Thyroid stunning. Thyroid 13: 333-340.

91. Mandel SJ, Shankar LK, Benard F, Yamamoto A, Alavi A, 2001 Superiority of iodine-123 compared with iodine131 scanning for thyroid remnants in patients with differentiated thyroid cancer. Clin Nucl Med 26: 6-9.

92. David A, Blotta A, Bondanelli M, et al, 2001 Serum thyroglobulin concentrations and (131)I whole-body scan results in patients with differentiated thyroid carcinoma after administration of recombinant human thyroid-stimulating hormone. J Nucl Med 42: 1470-1475.

93. Robbins RJ, Tuttle RM, Sharaf RN, et al, 2001 Preparation by recombinant human thyrotropin or thyroid hormone withdrawal are comparable for the detection of residual differentiated thyroid carcinoma. J Clin Endocrinol Metab 86: 619-625.
94. Robbins RJ, Robbins AK, 2003 Clinical review 156: Recombinant human thyrotropin and thyroid cancer management. J Clin Endocrinol Metab 88: 1933-1938.

95. Sherman SI, 2003 Thyroid carcinoma. Lancet 361: 501511.

96. Schlumberger M, Mancusi F, Baudin E, Pacini F, 1997 131-I therapy for elevated thyroglobulin levels. Thyroid 7: 273-276.

97. Mazzaferri EL, 1995 Treating high thyroglobulin with radioiodine: a magic bullet or a shot in the dark? J Clin Endocrinol Metab 80: 1485-1487.

98. Pineda JD, Lee T, Ain K, Reynolds JC, Robbins J, 1995 Iodine-131 therapy for thyroid cancer patients with elevated thyroglobulin and negative diagnostic scan. J Clin Endocrinol Metab 80: 1488-1492.

99. Robbins J, 1999 Management of thyroglobulin-positive, body scan-negative thyroid cancer patients: evidence for the utility of I-131 therapy. J Endocrinol Invest 22: 808810.

100. Pacini F, Agate L, Elisei R, et al, 2001 Outcome of differentiated thyroid cancer with detectable serum $\mathrm{Tg}$ and negative diagnostic (131)I whole body scan: comparison of patients treated with high (131)I activities versus untreated patients. J Clin Endocrinol Metab 86: 4092-4097.

101. McDougall IR, 1997 131I treatment of 131I negative whole body scan, and positive thyroglobulin in differentiated thyroid carcinoma: what is being treated? Thyroid 7: 669-672.

102. Kabasakal L, 2003 Treatment of iodine negative, thyroglobulin positive, thyroid cancer patients: do we miss the target when we shoot in the dark? Nucl Med Commun 24: 739-741.

103. Schultz PN, Stava C, Vassilopoulou-Sellin R, 2003 Health profiles and quality of life of 518 survivors of thyroid cancer. Head Neck 25: 349-356.

104. Chen AY, Levy L, Goepfert H, Brown BW, Spitz MR, Vassilopoulou-Sellin R, 2001 The development of breast carcinoma in women with thyroid carcinoma. Cancer 92: 225-231.

105. Maruca J, Santner S, Miller K, Santen RJ, 1984 Prolonged iodine clearance with a depletion regimen for thyroid carcinoma: concise communication. J Nucl Med 25: 10891093.

106. Lakshmanan M, Schaffer A, Robbins J, Reynolds J, Norton J, 1988 A simplified low iodine diet in I-131 scanning and therapy of thyroid cancer. Clin Nucl Med 13: 866-868.

107. Greenler DP, Klein HA, 1989 The scope of false-positive iodine-131 images for thyroid carcinoma. Clin Nucl Med 14: 111-117.

108. Chung JK, Lee YJ, Jeong JM, et al, 1997 Clinical significance of hepatic visualization on iodine-131 whole-body scan in patients with thyroid carcinoma. J Nucl Med 38: 1191-1195.

109. Shah DH, Samuel AM, 1996 Metastasis to the liver in welldifferentiated carcinoma of the thyroid. Thyroid 6: 607611.

110. Antonelli A, Miccoli P, Ferdeghini M, et al, 1995 Role of 
neck ultrasonography in the follow-up of patients operated on for thyroid cancer. Thyroid 5: 25-28.

111. Robbins J, Merino MJ, Boice JD, et al, 1991 Thyroid cancer: a lethal endocrine neoplasm. Ann Intern Med 115: 133-147.

112. Schlumberger M, Arcangioli O, Piekarski JD, Tubiana M, Parmentier C, 1988 Detection and treatment of lung metastases of differentiated thyroid carcinoma in patients with normal chest X-rays. J Nucl Med 29: 1790-1794.

113. Piekarski JD, Schlumberger M, Leclere J, Couanet D, Masselot J, Parmentier C, 1985 Chest computed tomography $(\mathrm{CT})$ in patients with micronodular lung metastases of differentiated thyroid carcinoma. Int J Radiat Oncol Biol Phys 11: 1023-1027.

114. Braverman LE, 1994 Iodine and the thyroid: 33 years of study. Thyroid 4: 351-356.

115. Sarlis NJ, Gourgiotis L, Guthrie LC, et al, 2003 In-111 DTPA-octreotide scintigraphy for disease detection in metastatic thyroid cancer: comparison with F-18 FDG positron emission tomography and extensive conventional radiographic imaging. Clin Nucl Med 28: 208-217.

116. Beierwaltes WH, 1987 Radioiodine therapy of thyroid disease. Int J Rad Appl Instrum B 14: 177-181.

117. Rall JE, Foster CG, Robbins J, Lazerson R, Farr LE, Rawson RW, 1953 Dosimetric considerations in determining hematopoietic damage from radioactive iodine. Am J Roentgenol Radium Ther Nucl Med 70: 274-282.

118. Benua RS, Cicale NR, Sonenberg M, Rawson RW, 1962 The relation of radioiodine dosimetry to results and complications in the treatment of metastatic thyroid cancer. Am J Roentgenol Radium Ther Nucl Med 87: 171-182.

119. Maxon HR, 1999 Quantitative radioiodine therapy in the treatment of differentiated thyroid cancer. Q J Nucl Med 43: 313-323.

120. Van Nostrand D, Neutze J, Atkins F, 1986 Side effects of "rational dose" iodine-131 therapy for metastatic welldifferentiated thyroid carcinoma. J Nucl Med 27: 15191527.

121. Koong SS, Reynolds JC, Movius EG, et al, 1999 Lithium as a potential adjuvant to $131 \mathrm{I}$ therapy of metastatic, well differentiated thyroid carcinoma. J Clin Endocrinol Metab 84: 912-916.

122. Edmonds CJ, Smith T, 1986 The long-term hazards of the treatment of thyroid cancer with radioiodine. Br $\mathbf{J}$ Radiol 59: 45-51.

123. Mandel SJ, Mandel L, 2003 Radioactive iodine and the salivary glands. Thyroid 13: 265-271.

124. Menzel C, Grunwald F, Schomburg A, et al, 1996 "Highdose" radioiodine therapy in advanced differentiated thyroid carcinoma. J Nucl Med 37: 1496-1503.

125. Maxon HR, Thomas SR, Hertzberg VS, et al, 1983 Relation between effective radiation dose and outcome of radioiodine therapy for thyroid cancer. N Engl J Med 309: 937-941.

126. Pak H, Gourgiotis L, Chang WI, et al, 2003 Role of metastasectomy in the management of thyroid carcinoma: the NIH experience. J Surg Oncol 82: 10-18.

127. Brierley JD, Tsang RW, 1999 External-beam radiation therapy in the treatment of differentiated thyroid cancer. Semin Surg Oncol 16: 42-49.

128. Brady LW, Markoe AM, Micaily B, Fisher SA, Lamm FR, 1990 Innovative techniques in radiation oncology. Clinical research programs to improve local and regional control in cancer. Cancer 65: 610-624.

129. Suntharalingam M, Haas ML, Conley BA, et al, 2000 The use of carboplatin and paclitaxel with daily radiotherapy in patients with locally advanced squamous cell carcinomas of the head and neck. Int J Radiat Oncol Biol Phys 47: 49-56.

130. Schlumberger M, Challeton C, De Vathaire F, Parmentier C, 1995 Treatment of distant metastases of differentiated thyroid carcinoma. J Endocrinol Invest 18: 170-172.

131. Gruning T, Tiepolt C, Zophel K, Bredow J, Kropp J, Franke WG, 2003 Retinoic acid for redifferentiation of thyroid cancer-does it hold its promise? Eur J Endocrinol 148: 395-402.

132. Grunwald F, Menzel C, Bender H, et al, 1998 Redifferentiation therapy-induced radioiodine uptake in thyroid cancer. J Nucl Med 39: 1903-1906.

133. Kitazono M, Robey R, Zhan Z, et al, 2001 Low concentrations of the histone deacetylase inhibitor, depsipeptide (FR901228), increase expression of the $\mathrm{Na}(+) / \mathrm{I}(-)$ symporter and iodine accumulation in poorly differentiated thyroid carcinoma cells. J Clin Endocrinol Metab 86: 3430-3435.

134. Fortunati N, Catalano MG, Arena K, Brignardello E, Piovesan A, Boccuzzi G, 2004 Valproic acid induces the expression of the $\mathrm{Na}+/ \mathrm{I}$ - symporter and iodine uptake in poorly differentiated thyroid cancer cells. J Clin Endocrinol Metab 89: 1006-1009.

135. Moretti F, Farsetti A, Soddu S, et al, 1997 p53 re-expression inhibits proliferation and restores differentiation of human thyroid anaplastic carcinoma cells. Oncogene 14: 729-740.

136. Carcangiu ML, Steeper T, Zampi G, Rosai J, 1985 Anaplastic thyroid carcinoma. A study of 70 cases. Am J Clin Pathol 83: 135-158.

137. Wolf BC, Sheahan K, DeCoste D, Variakojis D, Alpern HD, Haselow RE, 1992 Immunohistochemical analysis of small cell tumors of the thyroid gland: an Eastern Cooperative Oncology Group (ECOG) study. Hum Pathol 23: 1252-1261.

138. Ain KB, 1998 Anaplastic thyroid carcinoma: behavior, biology, and therapeutic approaches. Thyroid 8: 715-726.

139. McIver B, Hay ID, Giuffrida DF, et al, 2001 Anaplastic thyroid carcinoma: a 50-year experience at a single institution. Surgery 130: 1028-1034.

140. Pierie JP, Muzikansky A, Gaz RD, Faquin WC, Ott MJ, 2002 The effect of surgery and radiotherapy on outcome of anaplastic thyroid carcinoma. Ann Surg Oncol 9: 5764.

141. Levendag PC, De Porre PM, van Putten WL, 1993 Anaplastic carcinoma of the thyroid gland treated by radiation therapy. Int J Radiat Oncol Biol Phys 26: 125-128.

142. Asakawa H, Kobayashi T, Komoike Y, et al, 1997 Chemosensitivity of anaplastic thyroid carcinoma and 
poorly differentiated thyroid carcinoma. Anticancer Res 17: 2757-2762.

143. De Besi P, Busnardo B, Toso S, et al, 1991 Combined chemotherapy with bleomycin, adriamycin, and platinum in advanced thyroid cancer. J Endocrinol Invest 14: 475480.

144. Ain KB, Egorin MJ, DeSimone PA, 2000 Treatment of anaplastic thyroid carcinoma with paclitaxel: phase 2 trial using ninety-six-hour infusion. Collaborative Anaplastic Thyroid Cancer Health Intervention Trials $(\mathrm{CATCH}-$ IT) Group. Thyroid 10: 587-594.

145. Pietras K, Stumm M, Hubert M, et al, 2003 STI571 enhances the therapeutic index of epothilone $\mathrm{B}$ by a tumorselective increase of drug uptake. Clin Cancer Res 9:3779. 3787.

146. Schull B, Kornek GV, Schmid K, et al, 2003 Effective combination chemotherapy with bimonthly docetaxel and cisplatin with or without hematopoietic growth factor support in patients with advanced gastroesophageal cancer. Oncology 65: 211-217.

147. Pasieka JL, 2003 Anaplastic thyroid cancer. Curr Opin Oncol 15: 78-83.

148. Guyetant S, Josselin N, Savagner F, Rohmer V, Michalak S, Saint-Andre JP, 2003 C-cell hyperplasia and medullary thyroid carcinoma: clinicopathological and genetic correlations in 66 consecutive patients. Mod Pathol 16: 756-763.

149. Hocevar M, Bergant D, Auersperg M, Golouh R, 2001 Medullary carcinoma of the thyroid with serotonin production and carcinoid-like syndrome. Eur J Surg Oncol 27: 219-222.

150. Aniszewski JP, Young WF Jr, Thompson GB, Grant CS, van Heerden JA, 2001 Cushing syndrome due to ectopic adrenocorticotropic hormone secretion. World J Surg 25: 934-940.

151. Tagliabue M, Pagani A, Palestini N, Manieri C, Martina V, 1996 Multiple endocrine neoplasia (MEN IIB) with Cushing's syndrome due to medullary thyroid carcinoma producing corticotropin-releasing hormone. Panminerva Med 38: 41-44.

152. Rasmusson B, 1984 Gastro-intestinal polypeptides in patients treated for medullary carcinoma of the thyroid. Acta Endocrinol 106: 112-115.

153. Sizemore GW, 1987 Medullary carcinoma of the thyroid gland. Semin Oncol 14: 306-314.

154. Ruppert JM, Eggleston JC, deBustros A, Baylin SB, 1986 Disseminated calcitonin-poor medullary thyroid carcinoma in a patient with calcitonin-rich primary tumor. Am J Surg Pathol 10: 513-518.

155. Bojunga J, Dragan C, Schumm-Draeger PM, Usadel KH, Kusterer K, 2001 Circulating calcitonin and carcinoembryonic antigen mRNA detected by RT-PCR as tumour markers in medullary thyroid carcinoma. Br J Cancer 85: 1546-1550.

156. Baudin E, Bidart JM, Bachelot A, et al, 2001 Impact of chromogranin A measurement in the work-up of neuroendocrine tumors. Ann Oncol 12: Suppl 2: 79-82.

157. Hoff AO, Cote GJ, Gagel RF, 2000 Multiple endocrine neoplasias. Annu Rev Physiol 62: 377-411.

158. Eng C, Clayton D, Schuffenecker I, et al, 1996 The relationship between specific RET proto-oncogene mutations and disease phenotype in multiple endocrine neoplasia type 2. International RET mutation consortium analysis. JAMA 276: 1575-1579.

159. Yip L, Cote GJ, Shapiro SE, et al, 2003 Multiple endocrine neoplasia type 2: evaluation of the genotype-phenotype relationship. Arch Surg 138: 409-416.

160. Wohllk N, Cote GJ, Bugalho MM, et al, 1996 Relevance of RET proto-oncogene mutations in sporadic medullary thyroid carcinoma. J Clin Endocrinol Metab 81: 37403745.

161. Freyer G, Ligneau B, Schlumberger M, et al, 2001 Quality of life in patients at risk of medullary thyroid carcinoma and followed by a comprehensive medical network: trends for future evaluations. Ann Oncol 12: 1461-1465.

162. Saad MF, Ordonez NG, Rashid RK, et al, 1984 Medullary carcinoma of the thyroid. A study of the clinical features and prognostic factors in 161 patients. Medicine 63: 319-342.

163. O'Riordain DS, O'Brien T, Weaver AL, et al, 1994 Medullary thyroid carcinoma in multiple endocrine neoplasia types 2A and 2B. Surgery 116: 1017-1023.

164. Hyer SL, Vini L, A'Hern R, Harmer C, 2000 Medullary thyroid cancer: multivariate analysis of prognostic factors influencing survival. Eur J Surg Oncol 26: 686-690.

165. Brandi ML, Gagel RF, Angeli A, et al, 2001 Guidelines for diagnosis and therapy of MEN type 1 and type 2. J Clin Endocrinol Metab 86: 5658-5671.

166. Brierley J, Tsang R, Simpson WJ, Gospodarowicz M, Sutcliffe S, Panzarella T, 1996 Medullary thyroid cancer: analyses of survival and prognostic factors and the role of radiation therapy in local control. Thyroid 6: 305-310.

167. Krausz Y, Rosler A, Guttmann H, et al, 1999 Somatostatin receptor scintigraphy for early detection of regional and distant metastases of medullary carcinoma of the thyroid. Clin Nucl Med 24: 256-260.

168. Castellani MR, Alessi A, Savelli G, Bombardieri E, 2003 The role of radionuclide therapy in medullary thyroid cancer. Tumori 89: 560-562.

169. Malamitsi J, Kosmidis PA, Papadopoulos S, Petounis A, Linos DA, 2002 Contribution of an Anti-CEA Fab' scan in the detection of medullary thyroid cancer. Clin Nucl Med 27: 447-448.

170. Crippa F, Alessi A, Gerali A, Bombardieri E, 2003 FDGPET in thyroid cancer. Tumori 89: 540-543.

171. Gourgiotis L, Sarlis NJ, Reynolds JC, VanWaes C, Merino MJ, Pacak K, 2003 Localization of medullary thyroid carcinoma metastasis in a multiple endocrine neoplasia type $2 \mathrm{~A}$ patient by $6-[18 \mathrm{~F}]$-fluorodopamine positron emission tomography. J Clin Endocrinol Metab 88: 637-641.

172. Abdelmoumene N, Schlumberger M, Gardet P, et al, 1994 Selective venous sampling catheterisation for localisation of persisting medullary thyroid carcinoma. Br J Cancer 69: 1141-1144.

173. Diez JJ, Iglesias P, 2002 Somatostatin analogs in the treatment of medullary thyroid carcinoma. J Endocrinol In- 
vest 25: 773-778.

174. Burman KD, Ringel MD, Wartofsky L, 1996 Unusual types of thyroid neoplasms. Endocrinol Metab Clin North Am 25: 49-68.

175. Minagawa A, Iitaka M, Suzuki M, et al, 2002 A case of primary mucoepidermoid carcinoma of the thyroid: molecular evidence of its origin. Clin Endocrinol 57: 551556.

176. Kyriakou D, Bizakis J, Papadakis C, et al, 1996 Primary thyroid non-Hodgkin's lymphomas: clinicopathological observations on patients living in the island of Crete. Haematologia 27: 129-133.

177. Giuffrida D, Attard M, Marasa L, et al, 2000 Thyroid carcinosarcoma, a rare and aggressive histotype: a case report. Ann Oncol 11: 1497-1499.

178. Sichel JY, Wygoda M, Dano I, Osin P, Elidan J, 1996 Fibrosarcoma of the thyroid in a man exposed to fallout from the Chernobyl accident. Ann Otol Rhinol Laryngol 105: 832-834.

179. Demidchuk EP, Lebron-Felis FA, Murav'ev GN, 1987 Lymphosarcoma of the thyroid gland. Klin Med 65: 114116.

180. Azar AR, Weynand B, Daumerie C, Coche E, 2003 Metastatic liposarcoma of the thyroid gland. Br J Radiol 76: 750-752.

181. Siddiqui MT, Evans HL, Ro JY, Ayala AG, 1998 Epithelioid haemangioendothelioma of the thyroid gland: a case report and review of literature. Histopathology 32: 473476.

182. Yu J, Steiner FA, Muench JP, et al, 2002 Juxtathyroidal neck soft tissue angiosarcoma presenting as an undifferentiated thyroid carcinoma. Thyroid 12: 427-432.

183. Tsang RW, Brierley JD, Asa SL, Sturgeon JF, 2003 Malignant teratoma of the thyroid: aggressive chemoradiation therapy is required after surgery. Thyroid 13: 401404.

184. Cohen JB, Troxell M, Kong CS, McDougall IR, 2003 Ec- topic intrathyroidal thymoma: a case report and review. Thyroid 13: 305-308.

185. Ohshima M, Momiyama T, Souda S, Kuratani T, Toda K, Hiasa Y, 1994 Primary plasmacytoma of the thyroid: a case report and comparative literature study between Western nations and Japan. Pathol Int 44: 645-651.

186. Mrad K, Abbes I, Ben Salah H, Ben Amor MH, Sassi S, Ben-Romdhane K, 2002 Langerhans cell histiocytosis of the thyroid: a rare disease not to be ignored. Ann Pathol 22: $35-38$

187. Powell JG, Goellner JR, Nowak LE, McIver B, 2003 Rosai-Dorfman disease of the thyroid masquerading as anaplastic carcinoma. Thyroid 13: 217-221.

188. Koutkia P, Safran H, Kahn C, 2001 Metastatic carcinoma mimicking primary thyroid cancer. Med Health R I 84: 204-206.

189. Lam KY, Lo CY, 1998 Metastatic tumors of the thyroid gland: a study of 79 cases in Chinese patients. Arch Pathol Lab Med 122: 37-41.

190. Nakhjavani MK, Gharib H, Goellner JR, van Heerden JA, 1997 Metastasis to the thyroid gland. A report of 43 cases. Cancer 79: 574-578.

191. Vodovnik A, 2002 Fine needle aspiration cytology of primary thyroid paraganglioma. Report of a case with cytologic, histologic and immunohistochemical features and differential diagnostic considerations. Acta Cytol 46: 11331137.

192. Kostoglou-Athanassiou I, Lekka-Katsouli I, Gogou L, Papagrigoriou L, Chatonides I, Kaldrymides P, 2002 Malignant struma ovarii: report of a case and review of the literature. Horm Res 58: 34-38.

193. Rotman-Pikielny P, Reynolds JC, Barker WC, Yen PM, Skarulis MC, Sarlis NJ, 2000 Recombinant human thyrotropin for the diagnosis and treatment of a highly functional metastatic struma ovarii. J Clin Endocrinol Metab 85: 237-244. 